\title{
OPEN $\mathrm{Bi}_{2} \mathrm{WO}_{6}-\mathrm{BiOCl}$ heterostructure with enhanced photocatalytic activity for efficient degradation of oxytetracycline
}

\author{
Mengfan Guo 1,4, Zhaobo Zhou ${ }^{3,4}$, Shengnan Yan², Pengfei Zhou' ${ }^{1}$, Feng Miao ${ }^{2}$, Shijun Liang ${ }^{2}$, \\ Jinlan Wang ${ }^{3}$ \& Xinyi Cui ${ }^{1 \bowtie}$
}

The application of $\mathrm{BiOCl}$ in photocatalysis has been restricted by its low utilization of solar energy and fast recombination of charge carriers. In this study, zero-dimensional (OD) $\mathrm{Bi}_{2} \mathrm{WO}_{6}$ nanoparticles/ two-dimensional (2D) layered $\mathrm{BiOCl}$ heterojunction composite was successfully constructed by facile hydrothermal and solvothermal methods. The most favorable sunlight photocatalytic activity was achieved for the as-prepared $\mathrm{Bi}_{2} \mathrm{WO}_{6}-\mathrm{BiOCl}$ composites with a ratio of $1 \%$. The photocatalytic rate and mineralization efficiency of one typical antibiotic (i.e., oxytetracycline) over $1 \% \mathrm{Bi}_{2} \mathrm{WO}_{6}-\mathrm{BiOCl}$ was about 2.7 and 5.3 times as high as that of BiOCl. Both experimental characterizations and density functional theory (DFT) calculations confirmed that the excellent photocatalytic performance mainly arised from the effective charge separation along the $\mathrm{Bi}_{2} \mathrm{WO}_{6}$ and $\mathrm{BiOCl}$ heterojunction interface. The effective electron transfer was driven by the internal electric field at the interfacial junction. In addition, $1 \% \mathrm{Bi}_{2} \mathrm{WO}_{6}-\mathrm{BiOCl}$ exhibited excellent stability, and no apparent deactivation was observed after 4 test cycles. Therefore, the $0 \mathrm{D} / 2 \mathrm{D} \mathrm{Bi}_{2} \mathrm{WO}_{6}-\mathrm{BiOCl}$ heterojunction showed a great potential for the photocatalytic degradation of emerging organic pollutants.

As the rapid progress of industrialization, the accumulation of organic contaminant in natural water body is of a great threaten to global environment and human health. Traditional organic contaminant removal technologies, such as physical adsorption, chemical oxidation, and biological degradation, are usually undesirable due to their low efficiency and high energy consumption ${ }^{1-3}$. Semiconductor-based photocatalysis has drawn great attention for their potential in directly utilizes solar energy for environmental pollution decomposition ${ }^{4}$.

Two-dimensional (2D) lamellar structures are promising photocatalysts owing to their high emission quantum yields, large charge carrier mobility, and short bulk diffusion length ${ }^{5}$. Bismuth oxychloride (BiOCl), with a special layer structure consisting of $\left[\mathrm{Bi}_{2} \mathrm{O}_{2}\right]^{2+}$ layers sandwiched between two slabs of halogen ions, has shown favorable photocatalytic performance and stability ${ }^{6}$. However, there are still some bottlenecks hindering its practical application, such as wide band gap and fast recombination of electron-hole pairs of single $\mathrm{BiOCl}^{7}$. Some efforts have been devoted to deal with those drawbacks, such as controlling exposed crystal facets ${ }^{8}$, varying morphology and size $e^{9,10}$, noble metal doping ${ }^{11,12}$, and constructing heterostructures ${ }^{13-15}$, etc. Among these methods, the fabrication of heterostructure is one of the most effective ways. Due to the difference of band gap and position between the two semiconductors, it can be expected that the formation of heterojunction can promote the separation of photogenerated electron-hole pairs and thus improve the photocatalytic efficiency ${ }^{16}$.

As one of the simplest Aurivillius phases, bismuth tungstate $\left(\mathrm{Bi}_{2} \mathrm{WO}_{6}\right)$ has received a lot of attention due to its special chemistry structure and excellent visible-light response properties ${ }^{17-19} \cdot \mathrm{Bi}_{2} \mathrm{WO}_{6}$ has suitable band edges $\left(\mathrm{E}_{\mathrm{CB}}=0.03 \mathrm{eV}, \mathrm{E}_{\mathrm{VB}}=2.93 \mathrm{eV}\right)^{20}$, and can match well with $\mathrm{BiOCl}\left(\mathrm{E}_{\mathrm{CB}}=-0.80 \mathrm{eV}, \mathrm{E}_{\mathrm{VB}}=1.09 \mathrm{eV}\right)$ to form a heterostructure ${ }^{13}$. Additionally, both $\mathrm{Bi}_{2} \mathrm{WO}_{6}$ and $\mathrm{BiOCl}$ belong to the layered Aurivillius family, consisting of $\left[\mathrm{Bi}_{2} \mathrm{O}_{2}\right]^{2+}$ layers sandwiched between two slabs of $\left[\mathrm{WO}_{4}\right]^{2-}$ or $\mathrm{Cl}$ ions, which render them ready to match well with each other ${ }^{21,22}$.

\footnotetext{
${ }^{1}$ State Key Laboratory of Pollution Control and Resource Reuse, School of the Environment, Nanjing University, Nanjing University, 163 Xianlin Avenue, Nanjing 210046, China. ${ }^{2}$ National Laboratory of Solid State Microstructures, School of Physics, Collaborative Innovation Center of Advanced, Microstructures Nanjing University, Nanjing 210093, China. ${ }^{3}$ Department of Physics, Southeast University, Nanjing 211189, China. ${ }^{4}$ These authors contributed equally: Mengfan Guo and Zhaobo Zhou. ${ }^{\varpi}$ email: lizzycui@nju.edu.cn
} 
Recently, construction of closely coupled 0D-2D heterojunction is effective to form composite materials with excellent photocatalytic efficiency ${ }^{23,24}$. Firstly, $0 \mathrm{D}$ nanoparticles have advantages of large surface area, short charge-migration distance and size-tunable optoelectronics, suggesting their promising photocatalysis potential. Moreover, tight interactions between 0 and 2D components can make $0 \mathrm{D}$ nanoparticles more dispersive and stable, while the enhanced charge transfer facilitated by 2D nanosheets can effectively inhibit the recombination of photo-excited charges ${ }^{25-27}$. Therefore, it might be a robust approach to boost the photocatalytic performance by constructing $0 \mathrm{D} \mathrm{Bi}_{2} \mathrm{WO}_{6}$ nanoparticle/2D $\mathrm{BiOCl}$ nanosheet heterojunction to improve the photocatalytic efficiency.

In the current work, a $0 \mathrm{D} \mathrm{Bi}_{2} \mathrm{WO}_{6}$ nanoparticles/2D $\mathrm{BiOCl}$ nanosheets heterojunction was fabricated via a facile hydrothermal and solvothermal process. Their photocatalytic performance towards oxytetracycline (OTC) degradation under simulated sunlight irradiation was systematically evaluated, and the photocatalytic degradation of model contaminant (i.e., phenol) was also conducted for comparison. Mechanism of the enhanced photocatalytic activity of $\mathrm{Bi}_{2} \mathrm{WO}_{6}-\mathrm{BiOCl}$ heterojunction was comprehensively explained by instrumental characterizations (such as photo-luminescence spectra, valence band X-ray photoelectron spectroscopy, and UV-Vis diffuse reflectance spectra) and density functional theoretical (DFT) calculations.

\section{Experimental section}

Synthesis of $\mathrm{Bi}_{2} \mathrm{WO}_{6}-\mathrm{BiOCl}$ heterojunction. $\mathrm{Bi}_{2} \mathrm{WO}_{6}$ nanoparticles were prepared by a modified solvothermal method ${ }^{28}$. Briefly, $1 \mathrm{mmol} \mathrm{Bi}\left(\mathrm{NO}_{3}\right)_{3} \cdot 5 \mathrm{H}_{2} \mathrm{O}$ and $0.5 \mathrm{mmol} \mathrm{Na}_{2} \mathrm{WO}_{4} \cdot 2 \mathrm{H}_{2} \mathrm{O}$ were dispersed in $10 \mathrm{~mL}$ ethylene glycol (EG), respectively. These two solutions were ultra-sonicated for $30 \mathrm{~min}$ to form uniform tungsten source and bismuth source. The tungsten source was then slowly added to bismuth source with continuous stirring. The mixture was transferred into $50 \mathrm{~mL}$ Teflon-lined stainless steel autoclave, and heated at $160^{\circ} \mathrm{C}$ for $10 \mathrm{~h}$. After being cooled to room temperature, the precipitate was washed with ethanol for three times and dried at $60^{\circ} \mathrm{C}$ for $12 \mathrm{~h}$ in air.

The $\mathrm{Bi}_{2} \mathrm{WO}_{6}-\mathrm{BiOCl}$ composites were fabricated by a previously reported method ${ }^{3}$. Briefly, $1 \mathrm{mmol}$ $\mathrm{Bi}\left(\mathrm{NO}_{3}\right)_{3} \cdot 5 \mathrm{H}_{2} \mathrm{O}$ and aliquots (i.e. $0.005 \mathrm{mmol}, 0.01 \mathrm{mmol}, 0.02 \mathrm{mmol}, 0.04 \mathrm{mmol}$ ) of $\mathrm{Bi}_{2} \mathrm{WO}_{6}$ were added in $10 \mathrm{~mL}$ distilled water at room temperature with vigorous stirring and ultra-sonication for $1 \mathrm{~h}$. After that, $10 \mathrm{~mL}$ of $0.1 \mathrm{~mol} \mathrm{~L}-1 \mathrm{KCl}$ aqueous solution was added to $\mathrm{Bi}\left(\mathrm{NO}_{3}\right)_{3} \cdot 5 \mathrm{H}_{2} \mathrm{O}$ solution by dropwise. The solution was vigorously stirred for $30 \mathrm{~min}$, and $1 \mathrm{M} \mathrm{NaOH}$ was then added to adjust $\mathrm{pH}$ value to 6.0 . The mixture was stirred for $1 \mathrm{~h}$, poured into a $50 \mathrm{~mL}$ Teflon-lined stainless steel autoclave, and heated up to $160{ }^{\circ} \mathrm{C}$ for $24 \mathrm{~h}$. After being cooled to room temperature, the white precipitate was collected and washed with distilled water for three times. The washed precipitate was then dried at $60^{\circ} \mathrm{C}$ for $12 \mathrm{~h}$ in air to get the $\mathrm{Bi}_{2} \mathrm{WO}_{6}-\mathrm{BiOCl}$ composites. According to $\mathrm{Bi}_{2} \mathrm{WO}_{6}$ mass in the reaction system, $\mathrm{Bi}_{2} \mathrm{WO}_{6}-\mathrm{BiOCl}$ samples were denoted as $0.5 \%, 1 \%, 2 \%$, and $4 \% \mathrm{Bi}_{2} \mathrm{WO}_{6}-\mathrm{BiOCl}$. The pure $\mathrm{BiOCl}$ were also obtained without the addtion of $\mathrm{Bi}_{2} \mathrm{WO}_{6}$ under the same condition. The $1 \%$ mixture were prepared by simply mechanical blending of $\mathrm{Bi}_{2} \mathrm{WO}_{6}$ and $\mathrm{BiOCl}$ at a ratio of $1 \%$.

Characterization. The powder X-ray diffraction (XRD) patterns were collected by an X-ray diffractometer (Bruker D-8 Advance) with $\mathrm{Cu}$ Ka radiation $(\lambda=0.15406 \mathrm{~nm})$. The $2 \theta$ ranged from $10^{\circ}$ to $80^{\circ}$ with a scanning rate of $8^{\circ} \mathrm{min}^{-1}$. The morphologies and compositions of $\mathrm{Bi}_{2} \mathrm{WO}_{6}, \mathrm{BiOCl}$, and $\mathrm{Bi}_{2} \mathrm{WO}_{6}-\mathrm{BiOCl}_{\text {composites }}$ were performed by scanning electron microscopy (SEM) and energy dispersive X-ray spectroscopy (EDS) on a FEI Nova-450 scanning electron microscopy. Transmission electron microscopy (TEM), high-resolution transmission electron microscopy (HR-TEM) images, and selected-area electron diffraction (SAED) pattern were recorded in a JEM-200CX instrument with an accelerating voltage $200 \mathrm{kV}$. X-ray photoelectron spectroscopy (XPS) measurements were carried out by a PHI 5000 Versa Probe spectrometer with an Mg Ka ray source, and the binding energies were calibrated to the $\mathrm{C} 1 \mathrm{~s}$ peak at $284.6 \mathrm{eV}$. The specific surface areas of samples were examined by nitrogen adsorption and desorption apparatus (NOVA, Quantachrome, USA) with BrunauerEmmett-Teller (BET) method. The light absorption properties of the samples were recorded by UV-Vis diffuse reflectance spectra (UV-Vis-DRS, Hitachi UV-3600) with $\mathrm{BaSO}_{4}$ as the reference. The photoluminescence spectra (PL) were obtained using Fluorescence spectrometry (HORIBA fluoromax-4) with excitation at $315 \mathrm{~nm}$. The electron spin resonance (ESR) signals of radicals ( $\mathrm{OH}$ and $\mathrm{O}_{2}^{-}$) were tested on the X-band Bruker A-200 spectrometer (Germany).

Photocatalytic activity measurements. The photocatalytic activities for degradation of oxytetracycline (OTC) and phenol were tested by using a $500 \mathrm{~W}$ Xe lamp (CEL-HXF500, AULTT, China) at ambient temperature, and the optical power density was maintained about $42 \mathrm{~mW} \mathrm{~cm}^{-2}$ measured by a radiometer (CEL-NP2000, AULTT). In a typical process, $30 \mathrm{mg}$ of the photocatalyst was dispersed in $30 \mathrm{~mL}$ OTC or phenol aqueous solution with a concentration of $20 \mathrm{ppm}$. Before irradiation, the solution was continuously stirred in the dark for $2 \mathrm{~h}$ to ensure the establishment of adsorption-desorption equilibrium. During the degradation test, $1 \mathrm{~mL}$ of suspension were taken at given time intervals, centrifuged, and filtered to obtain the suspernatant for OTC or phenol analysis. The concentrations of OTC and phenol were determined by high performance liquid chromatography (HPLC; Waters, e2695, Ireland) with a XBridge ${ }^{\text {tw }} \mathrm{C} 18$ column $(5 \mu \mathrm{m}, 4.6 \times 250 \mathrm{~mm})$ and a UV detector operated at $355 \mathrm{~nm}$ and $270 \mathrm{~nm}$, respectively. The mobile phase consisted of methanol and water (volume ratio: 60/40) at a flow rate of $1 \mathrm{~mL} \mathrm{m^{-1 }}$ for phenol analysis ${ }^{29}$, and $0.005 \mathrm{~mol} \mathrm{~L}^{-1}$ oxalic acid solution/methanol/acetonitrile $(60 / 20 / 20, v / v / v)$ with a flow rate of $0.4 \mathrm{~mL} \mathrm{~min}^{-1}$ for OTC analysis ${ }^{30}$. The mineralization of OTC and phenol were determined by the change of total organic carbon (TOC) in supernant on a total organic carbon analyser (Vario TOC, Elementar). 

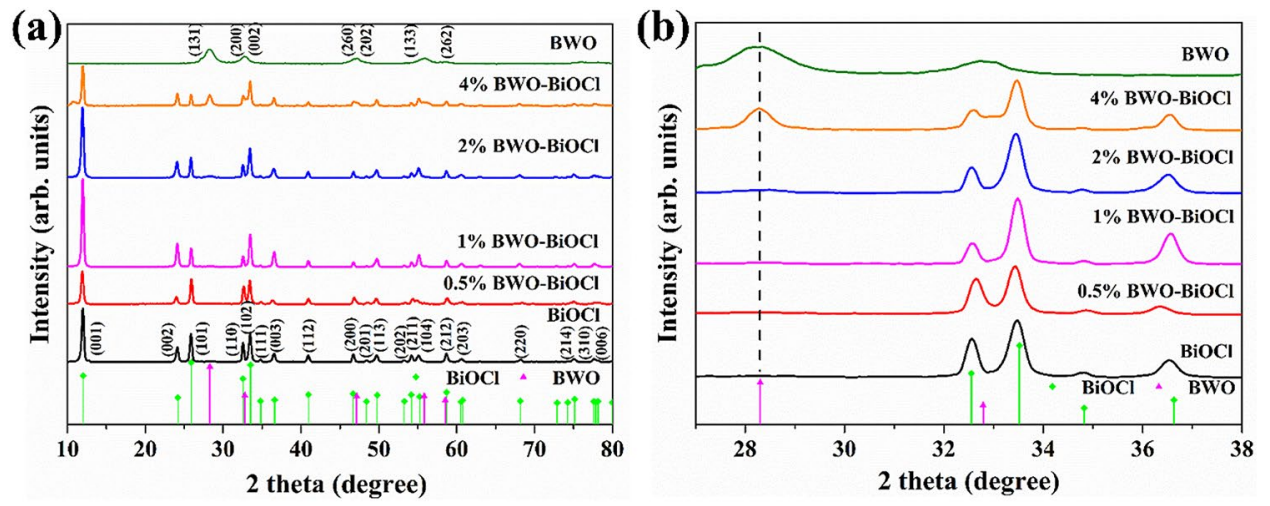

Figure 1. (a) XRD and (b) enlarged XRD patterns of $\mathrm{BiOCl}, \mathrm{Bi}_{2} \mathrm{WO}_{6}, 0.5 \%, 1 \%, 2 \%$, and $4 \% \mathrm{Bi}_{2} \mathrm{WO}_{6}-\mathrm{BiOCl}$.

Computational method. All the calculations were performed by means of density functional theory (DFT), as implemented in the Vienna Ab-initio Simulation Package (VASP) $)^{31,32}$ within the framework of the projector augmented wave (PAW) method ${ }^{33}$. The generalized gradient approximation (GGA) with the PerdewBurke-Ernzerhof (PBE) functional was utilized to describe the exchange correlation interactions ${ }^{34}$. A $500 \mathrm{eV}$ cutoff for the plane wave basis set was adopted in all computations. Structural relaxations were carried out until the residual forces on atoms less than $0.01 \mathrm{eV}^{-1}$. The convergence criterion of self-consistent calculations for ionic relaxations was set to $1 \times 10^{-5} \mathrm{eV}$ atom ${ }^{-1}$. The corresponding lattice parameter of unit cell for $\mathrm{Bi}_{2} \mathrm{WO}_{6} \mathrm{Was}$ calculated as $\mathrm{a}=5.55 \AA, \mathrm{b}=16.85 \AA$ and $\mathrm{c}=5.58 \AA$ and that for $\mathrm{BiOCl}$ was $\mathrm{a}=\mathrm{b}=3.91 \AA$ and $\mathrm{c}=7.84 \AA$, which were in good agreement with previous reports ${ }^{35,36}$. For the $\mathrm{Bi}_{2} \mathrm{WO}_{6}(020) / \mathrm{BiOCl}(010)$ interface model, a $3 \times 4$ $\mathrm{Bi}_{2} \mathrm{WO}_{6}(020)$ surface slab was used to match a $7 \times 3 \mathrm{BiOCl}(010)$ surface slab. The lattice mismatch between $3 \times 4$ $\mathrm{Bi}_{2} \mathrm{WO}_{6}(020)$ and $7 \times 3 \mathrm{BiOCl}(010)$ surface slabs is $3.82 \%$.

The vacuum space in the z-direction was set as large as $15 \AA$ to avoid interactions between the repeated slabs. A Monkhorst-Pack special k-point mesh of $1 \times 3 \times 1$ was proposed to carry out geometry optimization and electronic structure calculation. The charge-density difference $(\Delta \rho)$ was calculated by

$$
\Delta \rho=\Delta \rho \mathrm{Bi}_{2} \mathrm{WO}_{6}(020) / \mathrm{BiOCl}(010)-\Delta \rho \mathrm{BiOCl}(010)-\Delta \rho \mathrm{Bi}_{2} \mathrm{WO}_{6}(020)
$$

where $\Delta \rho \mathrm{Bi}_{2} \mathrm{WO}_{6}(020) / \mathrm{BiOCl}(010), \Delta \rho \mathrm{BiOCl}(010)$ and $\Delta \rho \mathrm{Bi}_{2} \mathrm{WO}_{6}(020)$ were the total charge density of the $\mathrm{Bi}_{2} \mathrm{WO}_{6}(020) / \mathrm{BiOCl}(010)$ heterostructures, $\mathrm{BiOCl}(010)$, and $\mathrm{Bi}_{2} \mathrm{WO}_{6}(020)$ surface slabs, respectively.

\section{Results and discussion}

Characterization of the catalysts. The phase structure and purity of the as-prepared $\mathrm{Bi}_{2} \mathrm{WO}_{6}, \mathrm{BiOCl}$, $0.5 \%, 1 \%, 2 \%$ and $4 \% \mathrm{Bi}_{2} \mathrm{WO}_{6}-\mathrm{BiOCl}$ were characterized by power $\mathrm{X}$-ray diffraction (XRD). As shown in Fig. 1a, the peak of all the photocatalysts were sharp and narrow, indicating that the samples possess single-phase and well-identified crystalline structures $\left(\mathrm{Bi}_{2} \mathrm{WO}_{6}\right.$ : JCPDS card no.39-0256; BiOCl: JCPDS card no. 85-0861). For pure $\mathrm{Bi}_{2} \mathrm{WO}_{6}$, a sharp peak at $28.3^{\circ}$ was assigned to (131) plane. While a series of typical peaks located in $12.0^{\circ}$, $24.1^{\circ}, 25.8^{\circ}, 32.5^{\circ}$ and $33.5^{\circ}$ were indexed as (001), (002), (101), (110) and (102) of BiOCl. The magnified part of XRD data from $27^{\circ}$ to $39^{\circ}$ are shown in Fig. $1 \mathrm{~b}$. With the augment of $\mathrm{Bi}_{2} \mathrm{WO}_{6}$ proportions, the peak intensity of the $\mathrm{Bi}_{2} \mathrm{WO}_{6}\left(28.3^{\circ}\right)$ gradually increased, and the relative peak intensity of the $\mathrm{BiOCl}$ was almost unchange. This indicated that compositing of $\mathrm{Bi}_{2} \mathrm{WO}_{6}$ cannot influence the crystal structure of $\mathrm{BiOCl}$.

The structure and morphology of the samples were characterized with scanning electron microscopy and energy dispersive X-ray spectroscopy (SEM-EDS) (Fig. 2).

SEM revealed that pure $\mathrm{Bi}_{2} \mathrm{WO}_{6}$ were nanoparticales with size of $5-10 \mathrm{~nm}$, and $\mathrm{BiOCl}$ consisted of nanosheets with size of $0.5-1 \mu \mathrm{m}$ (Fig. $2 \mathrm{a}, \mathrm{b}$ ). On the other hands, the morphology of $1 \% \mathrm{Bi}_{2} \mathrm{WO}_{6}-\mathrm{BiOCl}$ heterostructure is shown in Fig. $2 \mathrm{c}$. The surface element dispersion states of $1 \% \mathrm{Bi}_{2} \mathrm{WO}_{6}-\mathrm{BiOCl}$ was measured by EDS technology. Strong signals from $\mathrm{Bi}, \mathrm{Cl}, \mathrm{O}$ and $\mathrm{W}$ elements can be observed in EDS spectra (Fig. 2d). The atomic ratio of $\mathrm{Bi}: \mathrm{O}: \mathrm{Cl}: \mathrm{W}$ was $45: 36: 29: 1$ in the $1 \% \mathrm{Bi}_{2} \mathrm{WO}_{6}-\mathrm{BiOCl}$, indicating that $\mathrm{Bi}_{2} \mathrm{WO}_{6}$ was successfully incorporated with $\mathrm{BiOCl}$, which was consistent with XRD data.

Transmission electron microscopy (TEM) and selected-area electron diffraction (SAED) analyses were applied to further investigate the phase structure of $\mathrm{Bi}_{2} \mathrm{WO}_{6}$ nanoparticles, $\mathrm{BiOCl}$ nanosheets, and $1 \% \mathrm{Bi}_{2} \mathrm{WO}_{6}-\mathrm{BiOCl}$ heterojunctions. As shown in Fig. 3a, the $\mathrm{Bi}_{2} \mathrm{WO}_{6}$ sample exhibited nanoparticles with a size of 5-10 nm. The SAED pattern indicated the single-crystalline characteristic of the $\mathrm{Bi}_{2} \mathrm{WO}_{6}$ sample (Fig. $3 \mathrm{~b}$ ). The angle labled in the SAED pattern was $45^{\circ}$, which was in agreement with the theoretical value of the angle between the (200) and (202) planes. The set of diffraction spots can be indexed as the [010] zone axis of orthorhombic $\mathrm{Bi}_{2} \mathrm{WO}_{6}$. Figure $3 \mathrm{c}$ is the high-resolution TEM (HR-TEM) of $\mathrm{Bi}_{2} \mathrm{WO}_{6}$ sample, the interplanar lattice spacing of $0.273 \mathrm{~nm}$ corresponded to the (200) planes of $\mathrm{Bi}_{2} \mathrm{WO}_{6}$. Thus, it can be found that the main exposed facet of $\mathrm{Bi}_{2} \mathrm{WO}_{6}$ was $\{020\}$ facets. The TEM image of $\mathrm{BiOCl}$ sheets is illustrated in Fig. 3d, and the width of $\mathrm{BiOCl}$ was estimated to be $0.5-1 \mu \mathrm{m}$. The corresponding SAED pattern (Fig. 3e), indexed as the [010] zone, showed (200) and (102) planes with an interfacial angle of $46.6^{\circ}$, which was identical to the theoretical value. In HR-TEM image (Fig. 3f) of $\mathrm{BiOCl}$ nanosheet, the distances between adjacent lattice fringes were measured as 0.194 and 

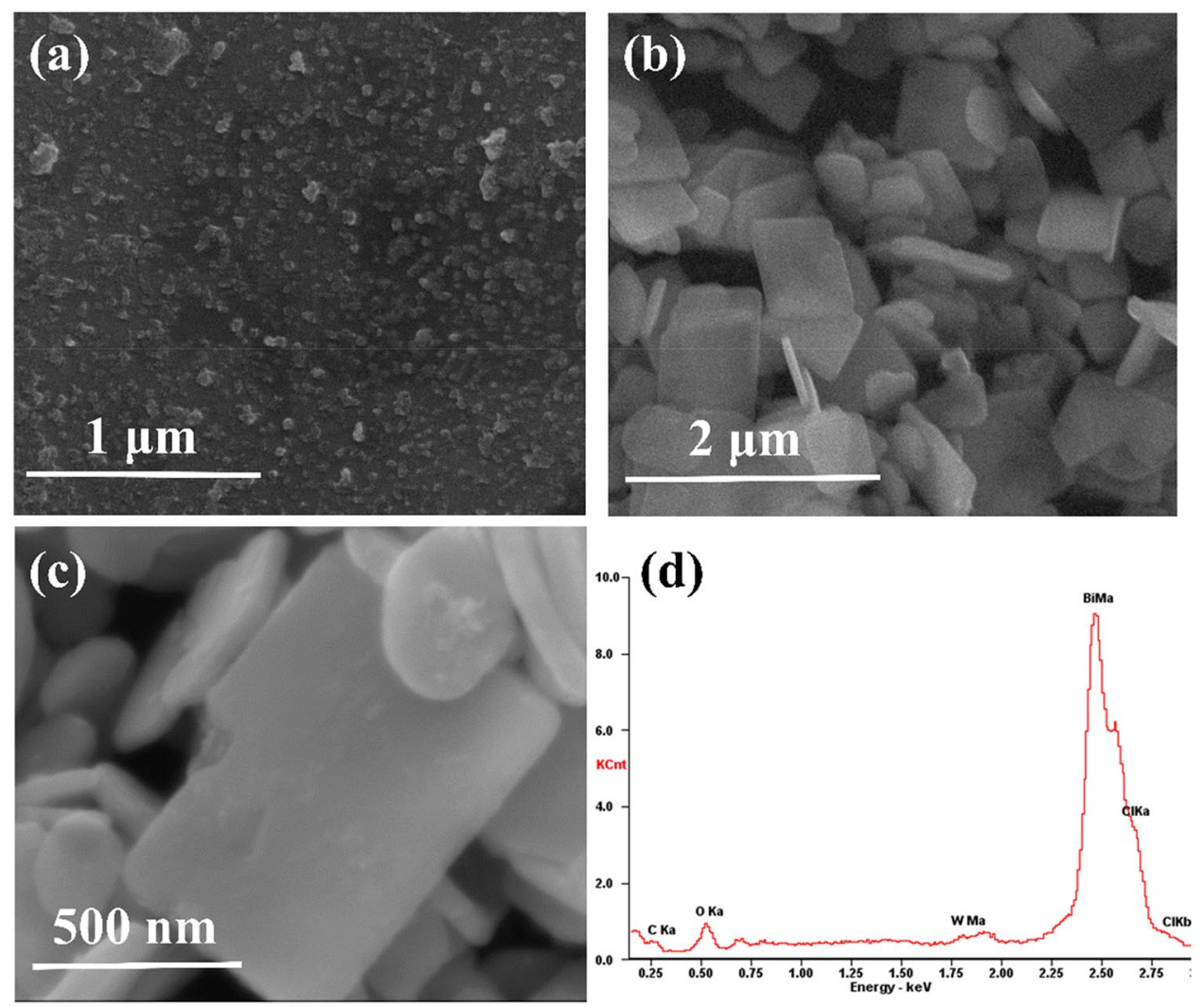

Figure 2. SEM images of (a) $\mathrm{Bi}_{2} \mathrm{WO}_{6}$, (b) $\mathrm{BiOCl}$ nanosheet, (c) $1 \% \mathrm{Bi}_{2} \mathrm{WO}_{6}-\mathrm{BiOCl}$, and (d) EDS spetra of $1 \%$ $\mathrm{Bi}_{2} \mathrm{WO}_{6}-\mathrm{BiOCl}$.

$0.267 \mathrm{~nm}$, respectively. This value corresponded to the interplanar distances of $\mathrm{BiOCl}(200)$ and (102), respectively. Therefore, these $\mathrm{BiOCl}$ nanosheets can be considered as enclosed by dominat $\{010\}$ facets. In theTEM and HR-TEM images of $1 \% \mathrm{Bi}_{2} \mathrm{WO}_{6}-\mathrm{BiOCl}$ (Fig. $3 \mathrm{~g}, \mathrm{~h}$ ), it can be clearly observed that some $\mathrm{Bi}_{2} \mathrm{WO}_{6}$ nanoparticles were anchored on the surface of $\mathrm{BiOCl}$ nanosheets. This result further demonstrated that $\mathrm{Bi}_{2} \mathrm{WO}_{6}-\mathrm{BiOCl}$ heterojunctions was formed in the composite. The formation of intimate interface contact is significant for promoting the charge separation to achieve high photocatalytic activity.

The surface element compositions, metal oxidation states, and valence state of $1 \% \mathrm{Bi}_{2} \mathrm{WO}_{6}-\mathrm{BiOCl}$ as well as the pure $\mathrm{BiOCl}$ were further characterized by XPS. All of the data were calibrated by $\mathrm{C}$ as reference $(284.6 \mathrm{eV})$. As shown in Fig. $4 \mathrm{a}$, the XPS spectra of pure $\mathrm{BiOCl}$ was composed of $\mathrm{Bi}, \mathrm{O}, \mathrm{Cl}$ peaks, and the $1 \% \mathrm{Bi}_{2} \mathrm{WO}_{6}-\mathrm{BiOCl}$ samples was comprised of $\mathrm{Bi}, \mathrm{O}, \mathrm{Cl}$ and $\mathrm{W}$. The high-resolution XPS spectra of $1 \% \mathrm{Bi}_{2} \mathrm{WO}_{6}-\mathrm{BiOCl}$ are further displayed in Fig. $4 \mathrm{~b}-\mathrm{e}$. The $\mathrm{Bi} 4 \mathrm{f}$. XPS spectra of $1 \% \mathrm{Bi}_{2} \mathrm{WO}_{6}-\mathrm{BiOCl}$ was deconvoluted in two peaks with binding energies (BE) of 159.1 and $164.3 \mathrm{eV}$, which were assigned to the $\mathrm{Bi}^{3+} 4 \mathrm{f}_{7 / 2}$ and $\mathrm{Bi}^{3+} 4 \mathrm{f}_{5 / 2}$ signals ${ }^{37,38}$. In Fig. $4 \mathrm{c}$, $\mathrm{O}^{2-} 1 \mathrm{~s}$ peak located at 530.0 and $531.8 \mathrm{eV}$ can be attributed to the surface lattice oxygen of $1 \% \mathrm{Bi}_{2} \mathrm{WO}_{6}-\mathrm{BiOCl}$ and binding hydroxyls of the water attached onto the surface ${ }^{39,40}$. In addition, the $\mathrm{Cl} 2 \mathrm{p}$ peaks associated with the bingding energy at $199.3 \mathrm{eV}$ and $197.9 \mathrm{eV}$ were all indexed to $\mathrm{Cl}^{-} 2 \mathrm{p}_{3 / 2}{ }^{41}$. While the peaks in Fig. $4 \mathrm{e}$ at 35.1 and $37.2 \mathrm{eV}$ were attributed to the surface $\mathrm{W}^{6+} 4 \mathrm{f}_{7 / 2}$ and $\mathrm{W}^{6+} 4 \mathrm{f}_{5 / 2}$, indicating the existence of $\mathrm{W}^{6+}$ oxidation state ${ }^{42}$.

The specific surface area and porosity of $\mathrm{BiOCl}$ and $\mathrm{Bi}_{2} \mathrm{WO}_{6}-\mathrm{BiOCl}$ were measured by the $\mathrm{N}_{2}$ adsorption-desorption method. Compared with $\mathrm{BiOCl}\left(26.6 \mathrm{~m}^{2} \mathrm{~g}^{-1}\right)$, surface area of $1 \% \mathrm{Bi}_{2} \mathrm{WO}_{6}-\mathrm{BiOCl}$ composite was relatively lower with a value of $14.8 \mathrm{~m}^{2} \mathrm{~g}^{-1}$, probably due to the deposition of $\mathrm{Bi}_{2} \mathrm{WO}_{6}$. The UV-Vis diffuse reflectance spectra (UV-Vis DRS) were conducted to determine the band gap energies of as-prepared samples. The pure $\mathrm{BiOCl}$ was a typical wide-band-gap semiconductor with an absorbtion edge about $415 \mathrm{~nm}$ (Fig. 5). A similar blue-shift of the absorption edge of $0.5 \%, 1 \%, 2 \% \mathrm{Bi}_{2} \mathrm{WO}_{6}-\mathrm{BiOCl}$ nanosheets could be observed when comparing with $\mathrm{BiOCl}$, and the absorbtion edge of $4 \% \mathrm{Bi}_{2} \mathrm{WO}_{6}-\mathrm{BiOCl}$ showed a obvious red-shift. Based on UV-Vis DRS, the band gap of as-prepared samples can be estimated according to the Kubelka-Munk equation ${ }^{43}$ :

$$
(\alpha h v)^{2}=\mathrm{A}\left(h v-E_{g}\right)^{\mathrm{n}}
$$

where $\alpha, h, v, \mathrm{~A}$, and $E_{g}$ were absorption coefficient, Planck's constant, light frequency, a constant, and band gap

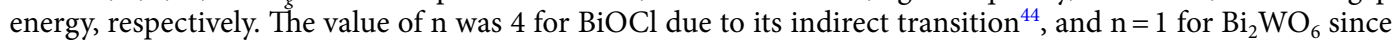
it was a direct-gap semiconductor ${ }^{45}$. By extrapolating the linear portion of the $(\alpha h v)^{2 / n}$ versus $h v$ curves to the energy axis at $(\alpha h v)^{2 / \mathrm{n}}=0$, the corresponding $E_{g}$ value were calculated to be $2.99,2.80,3.39,3.36,3.35$ and $2.37 \mathrm{eV}$ for $\mathrm{BiOCl}, \mathrm{Bi}_{2} \mathrm{WO}_{6}, 0.5 \%, 1 \%, 2 \%$, and $4 \% \mathrm{Bi}_{2} \mathrm{WO}_{6}-\mathrm{BiOCl}$, respectively. 

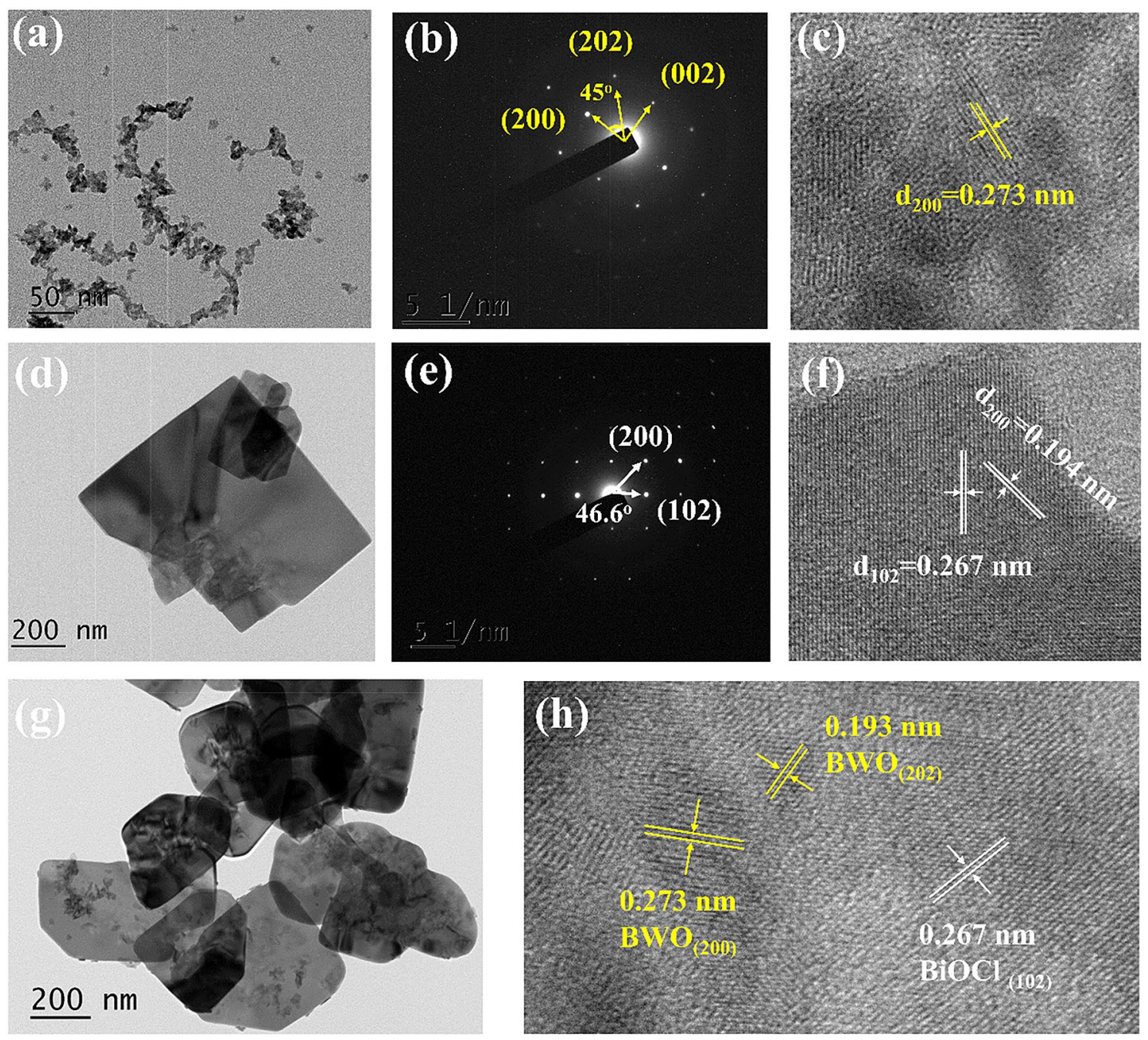

Figure 3. TEM and HR-TEM images of $(\mathbf{a}, \mathbf{c}) \mathrm{Bi}_{2} \mathrm{WO}_{6},(\mathbf{d}, \mathbf{f}) \mathrm{BiOCl}$ nanosheet, and (g,h) $1 \% \mathrm{Bi}_{2} \mathrm{WO}_{6}-\mathrm{BiOCl}$ composites, SAED patterns of $(\mathbf{b}) \mathrm{Bi}_{2} \mathrm{WO}_{6}$ and (e) $\mathrm{BiOCl}$.

Based on the valence band X-ray photoelectron spectra (Fig. 4f), the valance band maximum (VBM) of the $\mathrm{BiOCl}$ and $\mathrm{Bi}_{2} \mathrm{WO}_{6}$ were estimated to be 1.17 and $1.85 \mathrm{eV} v s \mathrm{NHE}$, respectively. According to the relation of $\mathrm{E}_{\mathrm{CB}}=\mathrm{E}_{\mathrm{VB}}-\mathrm{E}_{\mathrm{g}}$, the conduction band minimum $(\mathrm{CBM})$ of $\mathrm{BiOCl}$ and $\mathrm{Bi}_{2} \mathrm{WO}_{6}$ were estimated to be -1.82 and $-0.95 \mathrm{eV} v s \mathrm{NHE}$, respectively. These data indicated that the $\mathrm{CBM}$ and $\mathrm{VBM}$ of $\mathrm{BiOCl}$ and $\mathrm{Bi}_{2} \mathrm{WO}_{6}$ were at suitable positions to construct a heterojunction structure.

Photocatalytic activity and stability. The photocatalytic activities of the as-prepared samples were evaluated by degrading oxytetracycline (OTC) and phenol (20 ppm for each compound) under simulated sunlight irradiation. The $1 \% \mathrm{Bi}_{2} \mathrm{WO}_{6}-\mathrm{BiOCl}$ exhibited the highest photocatalytic acticity with $98.6 \%$ removal of OTC after $80 \mathrm{~min}$, while removal rates of $77.2 \%, 83.4 \%, 98.5 \%$, and $88.3 \%$ can be observed for $\mathrm{BiOCl}, 0.5 \%, 2 \%$, and $4 \% \mathrm{Bi}_{2} \mathrm{WO}_{6}-\mathrm{BiOCl}$ composites, respectively (Fig. 6a). More excellent performace can be observed for the degradation of phenol (Fig. 6b,d). No phenol degradation could be found in blank treatment under the simulated sunlight irradiation, indicating the stability of phenol. The $1 \% \mathrm{Bi}_{2} \mathrm{WO}_{6}-\mathrm{BiOCl}$ exhibited the highest photocatalytic activity with $93.4 \%$ removal of phenol after $5 \mathrm{~h}$. In addition, $\mathrm{Bi}_{2} \mathrm{WO}_{6}$ and $\mathrm{BiOCl}$ were simply mechanical mixed with a ratio of $1 \%$ (denoted as $1 \%$ mixture) for comparsion, and the phtocatalytic activity toward OTC declined to $79.4 \%$. This further implied that the heterojunction was formed between the interfaces of $\mathrm{Bi}_{2} \mathrm{WO}_{6}$ and $\mathrm{BiOCl}$, thus leading to the favorable photocatalytic performance.

In addition, the liner relationship of $-\ln \left(\mathrm{C}_{\mathrm{C}} \mathrm{C}_{0}\right) v s$ irradiation time $(\mathrm{t})\left(-\ln \left(\mathrm{C} / \mathrm{C}_{0}\right)=k \mathrm{t}\right)$ was investigated to simulate the degradation knietics. In this equation, $\mathrm{C}_{\mathrm{t}}, \mathrm{C}_{0}$, and $k$ were the OTC concentration after a certain reaction time $(\mathrm{t})$, initial OTC concentration, and apparent rate constant $\left(\mathrm{min}^{-1}\right)$, respectively. The photocatalysis of OTC were fitted well with pseudo first order reaction kinetics model. As shown in Fig. 6c, The rate constants $(k)$ was $0.018,0.017,0.021,0.049,0.049$, and $0.026 \mathrm{~min}^{-1}$ for $\mathrm{BiOCl}, 1 \%$ mixture, $0.5 \%, 1 \%, 2 \%$ and $4 \% \mathrm{Bi}_{2} \mathrm{WO}_{6}-\mathrm{BiOCl}$. To further explore the intrinstic photoreactivity, apparent reaction rate constant $(k)$ was normalized to the surface area, referred to $k_{s}$. The OTC degradation normalized reaction rate constant $\left(k_{s}\right)$ of $1 \% \mathrm{Bi}_{2} \mathrm{WO}_{6}-\mathrm{BiOCl}\left(33.1 \times 10^{-4} \mathrm{~min}^{-1} \mathrm{~g} \mathrm{~m}^{-2}\right)$ was 3.9 folds greater than that of $\mathrm{BiOCl}\left(6.8 \times 10^{-4} \mathrm{~min}^{-1} \mathrm{~g} \mathrm{~m}^{-2}\right)$. 

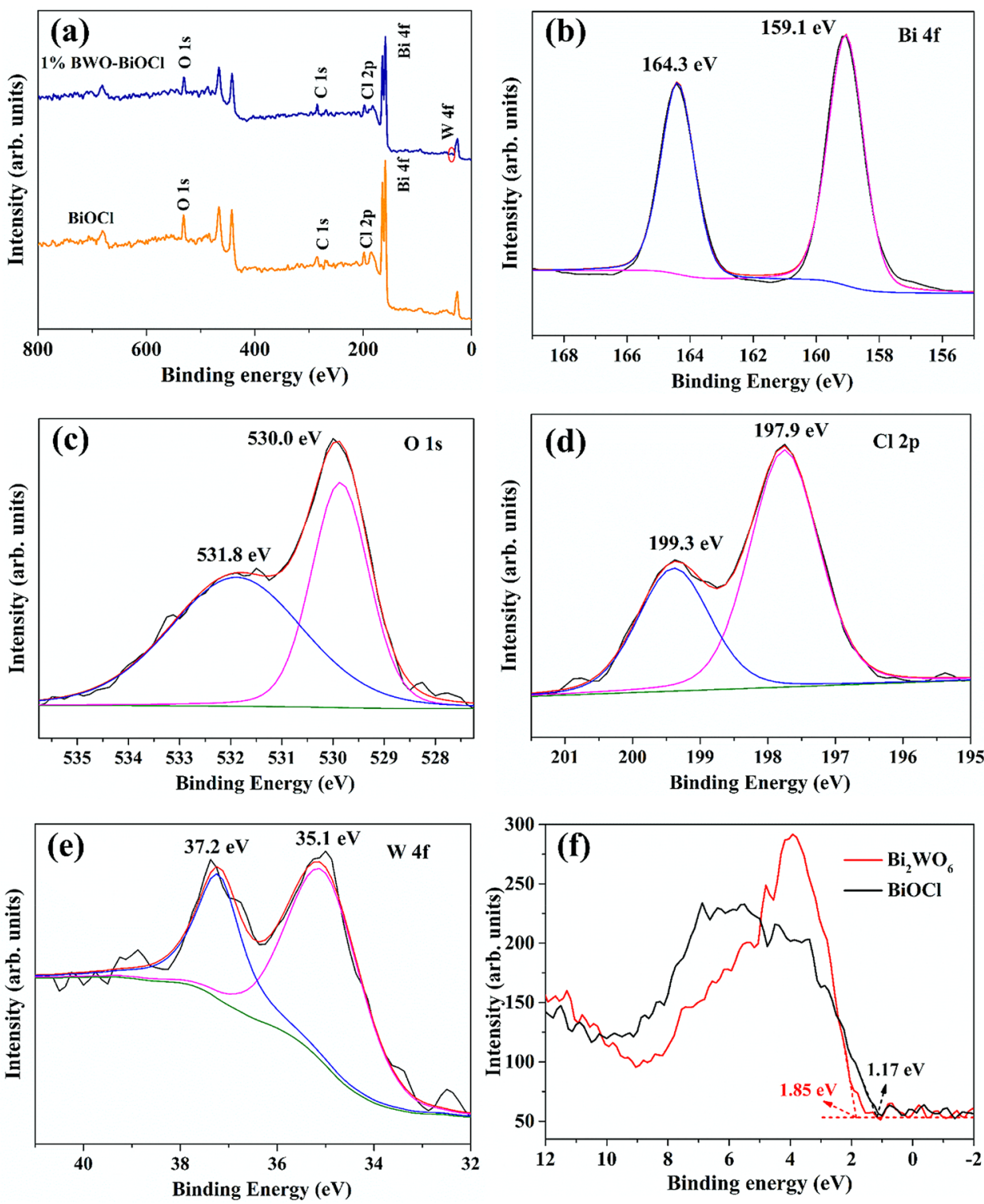

Figure 4. (a) XPS spectra of $\mathrm{BiOCl}$ and $1 \% \mathrm{Bi}_{2} \mathrm{WO}_{6}-\mathrm{BiOCl}$ nanosheet, and high revoluion XPS of (b) $\mathrm{Bi} 4 \mathrm{f}$., (c) $\mathrm{O} 1 \mathrm{~s},(\mathbf{d}) \mathrm{Cl} 2 \mathrm{p},(\mathbf{e}) \mathrm{W} 4 \mathrm{f}$. for $1 \% \mathrm{Bi}_{2} \mathrm{WO}_{6}-\mathrm{BiOCl}$, and (f) XPS valence band spectrums of $\mathrm{BiOCl}$ and $1 \%$ $\mathrm{Bi}_{2} \mathrm{WO}_{6}-\mathrm{BiOCl}$.
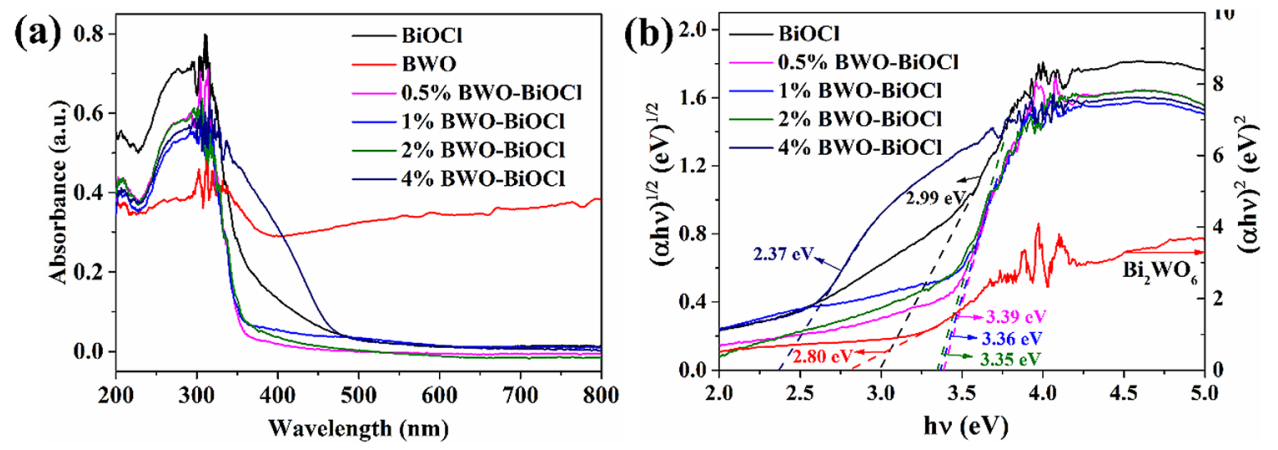

Figure 5. (a) UV-Vis diffuse reflectance spectra and (b) $(a h v)^{2 / \mathrm{n}}$ versus $h v$ plots attached band gap values of $\mathrm{BiOCl}, \mathrm{Bi}_{2} \mathrm{WO}_{6}, 0.5 \%, 1 \%, 2 \%$, and $4 \% \mathrm{Bi}_{2} \mathrm{WO}_{6}-\mathrm{BiOCl}$. 

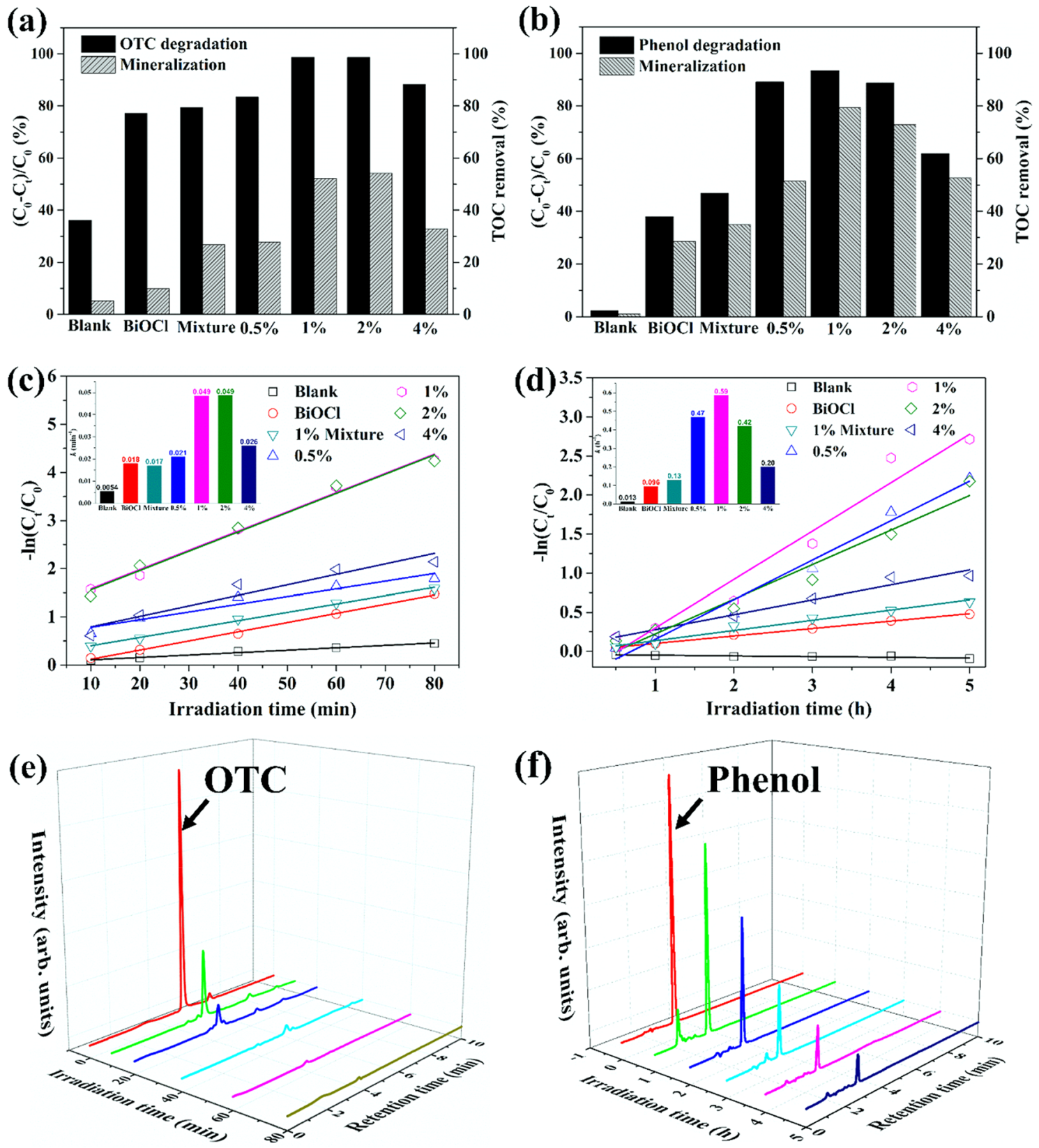

Figure 6. Photocatalytic degradation and mineralization rates of (a) OTC and (b) phenol, degradation kinetics of (c) OTC and (d) phenol over $\mathrm{BiOCl}, 1 \%$ mixture, $0.5 \%, 1 \%$, 2\%, and $4 \% \mathrm{Bi}_{2} \mathrm{WO}_{6}-\mathrm{BiOCl}$ composites, timedependent HPLC chromatograms of (e) OTC and (f) phenol degradation over $1 \% \mathrm{Bi}_{2} \mathrm{WO}_{6}-\mathrm{BiOCl}$.

Similarly, the $k_{s}$ for phenol degradation of $1 \% \mathrm{Bi}_{2} \mathrm{WO}_{6}-\mathrm{BiOCl}\left(39.9 \times 10^{-3} \mathrm{~h}^{-1} \mathrm{~g} \mathrm{~m}^{-2}\right)$ was also 10.1 folds higher than that of $\mathrm{BiOCl}\left(3.6 \times 10^{-3} \mathrm{~h}^{-1} \mathrm{~g} \mathrm{~m}^{-2}\right)$. The excellent photocatalytic performance of $1 \% \mathrm{Bi}_{2} \mathrm{WO}_{6}-\mathrm{BiOCl}$ under simulated sunlight irradiation can be also visualized through the time-dependent HPLC of OTC and phenol (Fig. 6e,f).

The mineralization rate, which was evaluated as the removal of total organic carbon (TOC), is crucial for evaluating photocatalyst performance. Similar with the degradation efficiency, the highest mineralization rate was measured for $1 \% \mathrm{Bi}_{2} \mathrm{WO}_{6}-\mathrm{BiOCl}$ with $52.2 \%$ of TOC romoval after 80 min under sunlight irradiation, which was 5.3-fold relative to that of pure $\mathrm{BiOCl}$ and 1.9 times that of $1 \%$ mixture (Fig. 6a). Similarly, the TOC values of phenol solution dramatically decreased from 18.63 to $1.98 \mathrm{mg} \mathrm{L}^{-1}$ after $5 \mathrm{~h}$ of sunlight irradiation, corresponding to $79.4 \%$ TOC removal, which was 2.8 times of that of $\mathrm{BiOCl}$ and 2.3 times that of $1 \%$ mixture (Fig. 6b). In addition, the photocatalytic degradation performance of phenol in related works is summarized for comparison (Table 1). Based on the parameters of degradation rate, it is obvious that $1 \% \mathrm{Bi}_{2} \mathrm{WO}_{6}-\mathrm{BiOCl}$ sample in the current study exhibited favorable photocatalytic degradation and mineralization performance.

The stability of the $1 \% \mathrm{Bi}_{2} \mathrm{WO}_{6}-\mathrm{BiOCl}$ nanosheets was investigated by cyclings of photodegradation tests. No apparent deactivation could be observed for OTC and phenol degradation after four test cycles (Fig. 7a,b). 


\begin{tabular}{|c|c|c|c|c|c|c|}
\hline Photocatalyst & Light source & Phenol (ppm) & $K\left(\mathrm{~h}^{-1}\right)$ & Degradation (\%) & Mineralization (\%) & References \\
\hline $\mathrm{Bi}_{2} \mathrm{WO}_{6} / \mathrm{BiOCl} 1 \mathrm{~g} / \mathrm{L}$ & $500 \mathrm{~W}$ Xe & 20 & 0.59 & $93 \%(5 \mathrm{~h})$ & $79.4 \%$ & This work \\
\hline $\mathrm{C}_{60} / \mathrm{BiOCl} 1 \mathrm{~g} / \mathrm{L}$ & $500 \mathrm{~W}$ Xe & 20 & 0.26 & $97 \%(12 \mathrm{~h})$ & - & 46 \\
\hline $\mathrm{BiOCl} / \mathrm{Bi}_{12} \mathrm{O}_{17} \mathrm{Cl}_{2} 0.6 \mathrm{~g} / \mathrm{L}$ & $500 \mathrm{~W}$ Xe & 10 & - & $46 \%(4 \mathrm{~h})$ & - & 47 \\
\hline $\mathrm{PDI} / \mathrm{Bi}_{2} \mathrm{WO}_{6} 0.5 \mathrm{~g} / \mathrm{L}$ & $500 \mathrm{~W} \mathrm{Xe}>420 \mathrm{~nm}$ & 5 & 0.36 & $67 \%(2 \mathrm{~h})$ & - & 48 \\
\hline $\mathrm{BiOBr}_{0.9} \mathrm{I}_{0.1} / \mathrm{BiOI} 0.8 \mathrm{~g} / \mathrm{L}$ & $500 \mathrm{~W}$ Xe $>420 \mathrm{~nm}$ & 10 & 0.088 & $50 \%(8 \mathrm{~h})$ & & 49 \\
\hline $\mathrm{TiO}_{2} / \mathrm{BiOCl} 1 \mathrm{~g} / \mathrm{L}$ & $300 \mathrm{~W}$ Xe $>450 \mathrm{~nm}$ & 50 & - & $55 \%(6 \mathrm{~h})$ & $50 \%$ & 50 \\
\hline $\mathrm{BiOCl} / \mathrm{Bi}_{2} \mathrm{MoO}_{6} 1 \mathrm{~g} / \mathrm{L}$ & $300 \mathrm{~W}$ Xe $>420 \mathrm{~nm}$ & 10 & - & $40 \%(4 \mathrm{~h})$ & - & 51 \\
\hline $\mathrm{Bi}_{2} \mathrm{WO}_{6} / \mathrm{RGO} 0.5 \mathrm{~g} / \mathrm{L}$ & Natural sunlight & 10 & - & $65 \%(8 \mathrm{~h})$ & $39.7 \%$ & 52 \\
\hline
\end{tabular}

Table 1. Summary of related photocatalyst systems for phenol degradation.
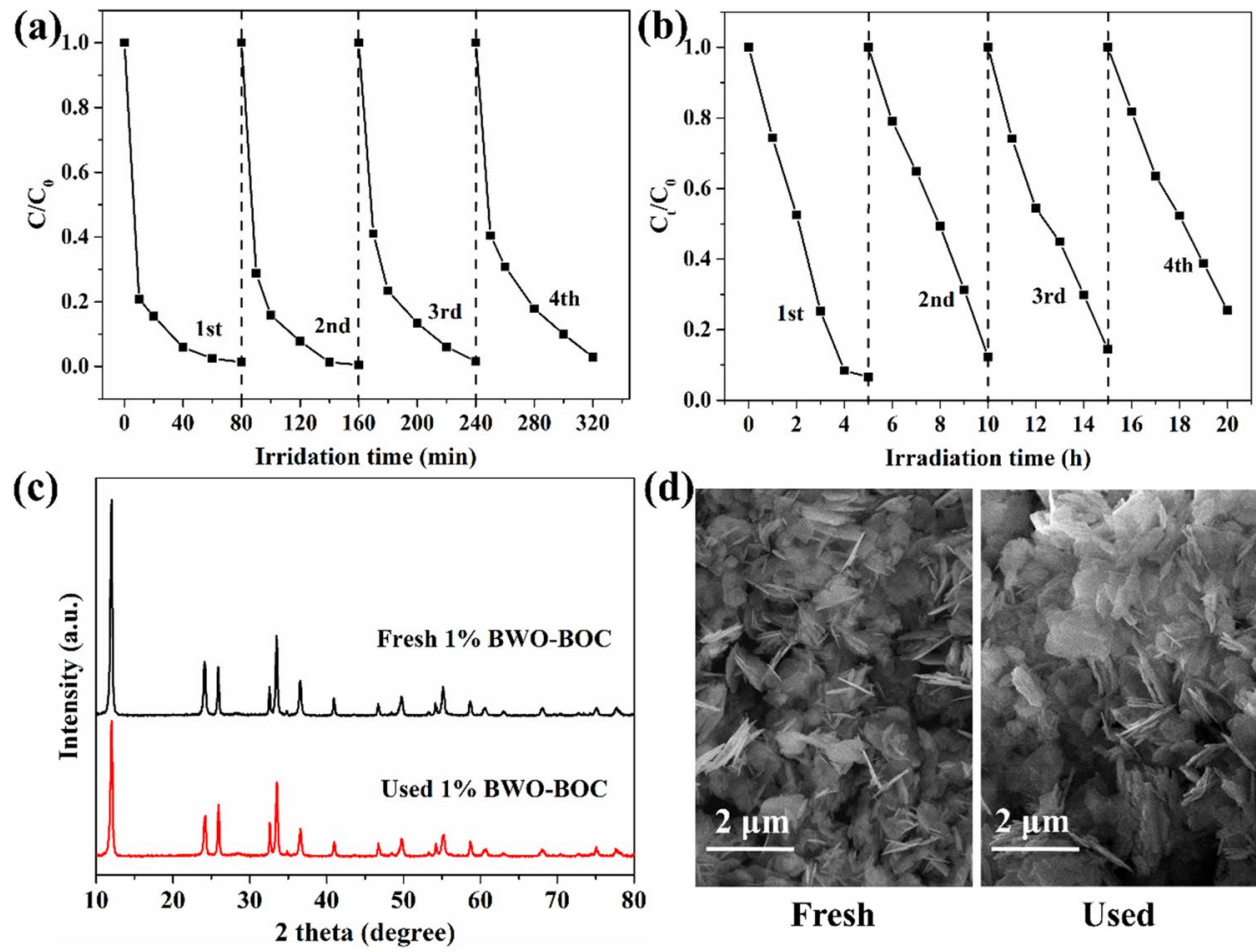

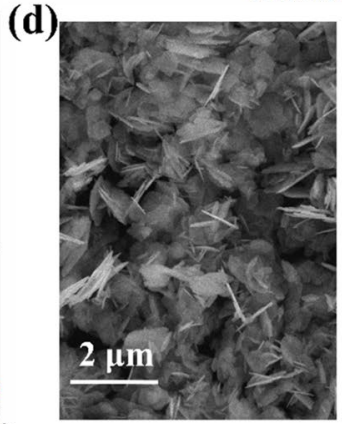

Fresh

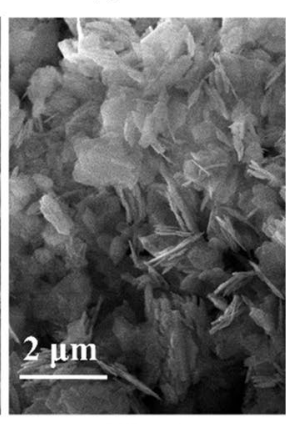

Used

Figure 7. Recycling tests of $1 \% \mathrm{Bi}_{2} \mathrm{WO}_{6}-\mathrm{BiOCl}$ for $(\mathbf{a}) \mathrm{OTC}\left(\mathrm{C}_{0}=20 \mathrm{ppm}\right),(\mathbf{b})$ phenol $\left(\mathrm{C}_{0}=20 \mathrm{ppm}\right)$ photocatalytic degradation under simulated sunlight irradiation, (c) XRD patterns and (d) SEM images of the fresh and used $(20 \mathrm{~h}) 1 \% \mathrm{Bi}_{2} \mathrm{WO}_{6}-\mathrm{BiOCl}$ for phenol degradation.

Morever, there was no significant changes between the fresh and used $1 \% \mathrm{Bi}_{2} \mathrm{WO}_{6}-\mathrm{BiOCl}$ samples through XRD pattern diffraction peaks (Fig. 7c) and SEM images (Fig. 7d), suggesting its favorable stability for the photocatalytic decomposition of environmental contaminants.

Mechanism of photocatalytic activity enhancement. The recombination of photogenerated electron-hole pairs is the primary cause for the emission of photoluminescence (PL). A higher PL intensity indicates a higher recombination rate of photoexcited electron-hole pairs ${ }^{53}$. As shown in Fig. 8, the pure BiOCl exhibited the strongest photoluminescence intensity, while the $\mathrm{PL}$ intensity of $\mathrm{Bi}_{2} \mathrm{WO}_{6}-\mathrm{BiOCl}$ samples decreased with the introduction of $\mathrm{Bi}_{2} \mathrm{WO}_{6}$. The weakest PL intensity was observed for $1 \% \mathrm{Bi}_{2} \mathrm{WO}_{6}-\mathrm{BiOCl}$ sample. It therefore can be concluded that the $\mathrm{Bi}_{2} \mathrm{WO}_{6}-\mathrm{BiOCl}$ heterojunctions could efficiently inhibit the recombination of photoexcited charge carriers.

On the basis of the HR-TEM results, a theoretical heterojunction model through contacting $\mathrm{Bi}_{2} \mathrm{WO}_{6}(020)$ plane and $\mathrm{BiOCl}(010)$ plane were constructed to investigate the charge transfer mechanism between $\mathrm{Bi}_{2} \mathrm{WO}_{6}$ and $\mathrm{BiOCl}$ interface. A $3 \times 4 \mathrm{Bi}_{2} \mathrm{WO}_{6}(020)$ surface slab and a $7 \times 3 \mathrm{BiOCl}(010)$ surface slab were matched to build the optimized $\mathrm{Bi}_{2} \mathrm{WO}_{6}(020) / \mathrm{BiOCl}(010)$ interface model with an energy minimization (Fig. 9a). The $\mathrm{Bi}_{2} \mathrm{WO}_{6}$ consisting of $\left[\mathrm{Bi}_{2} \mathrm{O}_{2}\right]$ layers sandwiched between two slabs of $\left[\mathrm{WO}_{4}\right]$, equally $\left[\mathrm{Bi}_{2} \mathrm{O}_{2}\right]$ and $[\mathrm{Cl}]$ layers intersected form $\mathrm{BiOCl}$ in the optimized crystal models, which were in good agreement with previous reports ${ }^{7}$. 


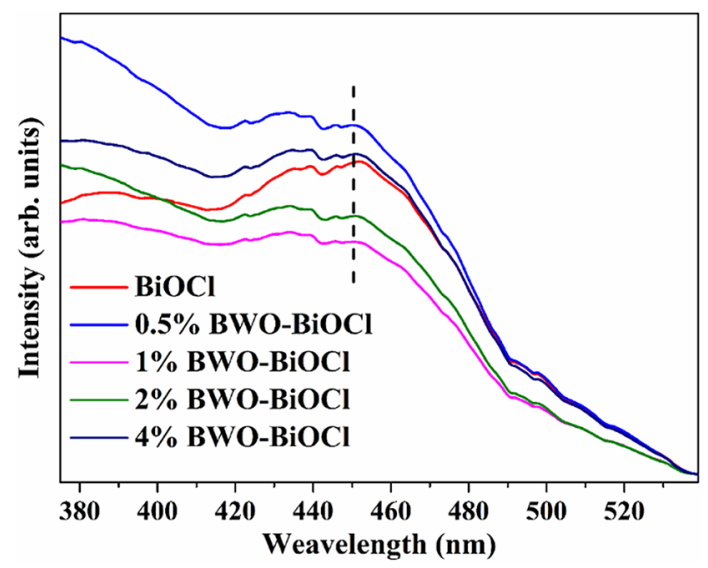

Figure 8. Photoluminescence (PL) spectra of $\mathrm{BiOCl}, 0.5 \%, 1 \%, 2 \%$, and $4 \% \mathrm{Bi}_{2} \mathrm{WO}_{6}-\mathrm{BiOCl}$.

(a)
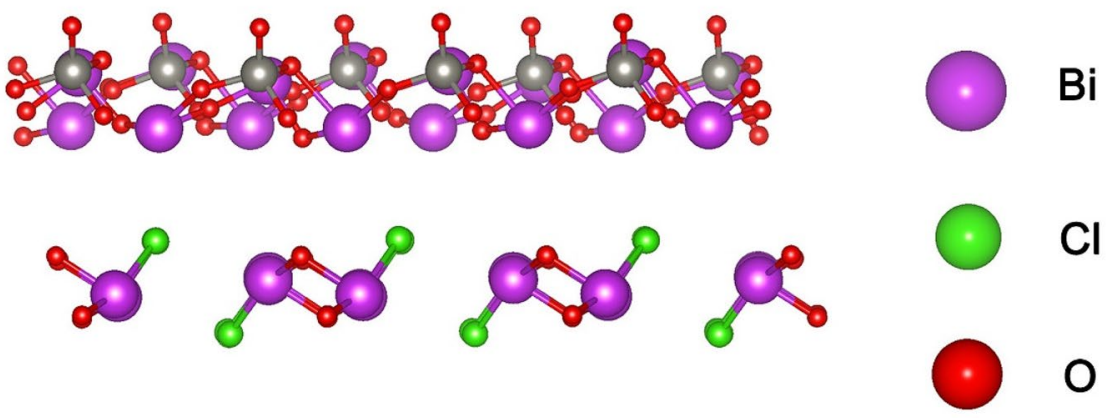

(b)
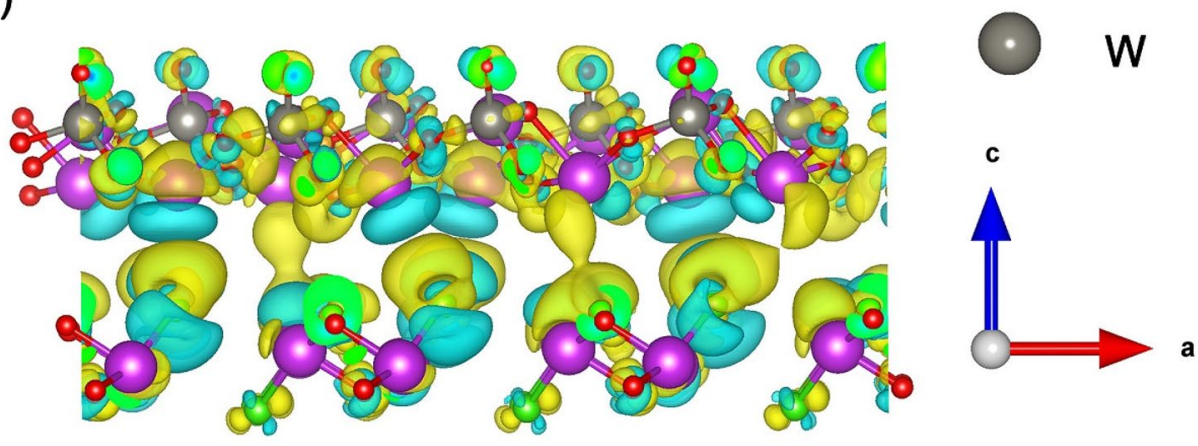

Figure 9. (a) Optimized crystal models, the $\mathrm{Bi}, \mathrm{Cl}, \mathrm{O}$ and $\mathrm{W}$ atoms are represented as purple, green, red and sliver, respectively. (b) Charge density difference map for the interfaces between $\mathrm{Bi}_{2} \mathrm{WO}_{6}(020)$ and $\mathrm{BiOCl}(010)$, the yellow region repersents charge accumulation and the cyan region indicates charge depletion.

To visualize the electron distribution the electron distributions, the electron difference density (EDD) maps and Bader charge analysis for $\mathrm{Bi}_{2} \mathrm{WO}_{6}(020) / \mathrm{BiOCl}(010)$ interface were performed. The EDD mappings showed that there was an interlacing behavior between the electron rich and deficient areas. Figure $9 \mathrm{~b}$ showed that electrons were deplected from $\mathrm{Bi}$ and $\mathrm{O}$ atoms of $\mathrm{Bi}_{2} \mathrm{WO}_{6}$ (as shown in cyan region), while they were accumulated in the $\mathrm{BiOCl}$ (as shown in yellow region), which indicated that electrons from $\mathrm{Bi}_{2} \mathrm{WO}_{6}$ could flow into $\mathrm{BiOCl}$.

Combining with Bader charge analysis (Table 2), it can be summarized that the electron density of $\mathrm{Bi}_{2} \mathrm{WO}_{6}$ (020) plane was more negative than that of $\mathrm{BiOCl}(010)$ plane in the $\mathrm{Bi}_{2} \mathrm{WO}_{6}(020) / \mathrm{BiOCl}(010)$ interface. This electron distribution resulted in a heterojunction interface electric field pointed from $\mathrm{Bi}_{2} \mathrm{WO}_{6}(020)$ to $\mathrm{BiOCl}$ (010) along the (010) direction. The built-in electric field at the interface served as a driving force to rapidly separate the photo-generated electrons and enhance photocatalytic activity.

The reactive species trapping experiments were conducted to further explore the possible photocatalytic mechanisms over the $1 \% \mathrm{Bi}_{2} \mathrm{WO}_{6}-\mathrm{BiOCl}$ sample. Ascorbic acid (AA, $5 \mathrm{mM}$ ), isopropanol (IPA, $5 \mathrm{mM}$ ), and sodiun oxalate $(\mathrm{SO}, 5 \mathrm{mM})$ were used as scavengers for superoxide radical $\left(\mathrm{O}_{2}^{-}\right)$, hydroxyl radical $\left({ }^{\circ} \mathrm{OH}\right)$, and holes $\left(\mathrm{h}^{+}\right)^{54}$, respectively. The OTC conversion slightly decreased with the addition of IPA and SO (Fig. 10a). In 


\begin{tabular}{|l|l|l|l|l|}
\hline \multirow{2}{*}{ Species } & \multicolumn{4}{|l|}{ Bader charge analysis } \\
\cline { 2 - 5 } & $\mathbf{B i}$ & $\mathbf{O}$ & $\mathrm{Cl}$ & W \\
\hline $\mathrm{BiOCl}(010)$ & 1.75 & -1.12 & -0.63 & - \\
\hline $\mathrm{Bi}_{2} \mathrm{WO}_{6}(020)$ & 1.80 & -1.04 & - & 2.64 \\
\hline
\end{tabular}

Table 2. Bader charge population on the $\mathrm{Bi}, \mathrm{O}, \mathrm{Cl}$, and $\mathrm{W}$ for $\mathrm{Bi}_{2} \mathrm{WO}_{6}(020) / \mathrm{BiOCl}(010)$ heterojunctions.
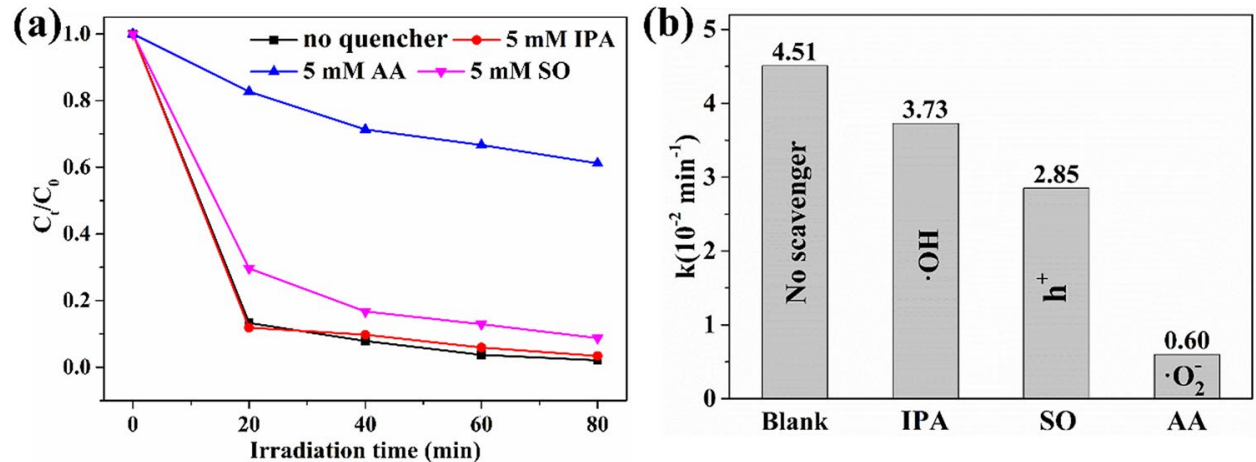

(c)

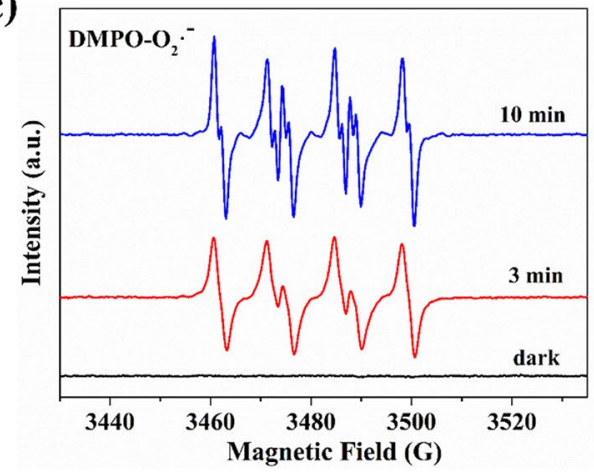

(d)

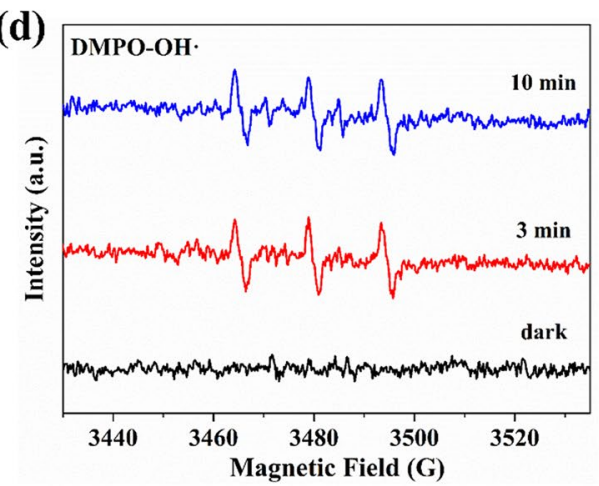

Figure 10. (a) Photocatalytic degradation of $\mathrm{OTC}$ over $1 \% \mathrm{Bi}_{2} \mathrm{WO}_{6}-\mathrm{BiOCl}$ in the presence of scavengers under simulated sunlight irradiation, (b) Psedo first-order kinetic fitting and the determined apparent rate constants (k) with different quenchers, ESR spectra of (c) DMPO- $\mathrm{O}_{2}^{-}$, and (d) DMPO- $\mathrm{OH}$ over $1 \% \mathrm{Bi}_{2} \mathrm{WO}_{6}-\mathrm{BiOCl}$ samples.

contrast, OTC conversion significantly dropped from $98.9 \%$ to $38.8 \%$ within 80 min of sunlight illumination when AA were added. The photocatalytic degradation pseudo-first order kinetics constant of OTC decreased from 0.0415 to $0.0373,0.0285$ and $0.006 \mathrm{~min}^{-1}$ with adding of IPA, SO and AA (Fig. 10b). This demonstrated that the photocatalytic process was mainly governed by the $\mathrm{O}_{2}^{-}$, and the role of $\mathrm{h}^{+}$cannot be ignored in this system.

ESR spin trap technique was employed to study the main reactive oxygen species generated by $1 \%$ $\mathrm{Bi}_{2} \mathrm{WO}_{6}-\mathrm{BiOCl}$. The 5,5-dimethyl-1-pyrroline $\mathrm{N}$-oxide (DMPO) was used to capture the $\mathrm{O}_{2}{ }^{-}$and $\mathrm{OH}$. After irradiation for $3 \mathrm{~min}$ and $10 \mathrm{~min}$, the special spectrum with an intensity ratio of 1:1:1:1 quartet signal was obviously observed in $1 \% \mathrm{Bi}_{2} \mathrm{WO}_{6}-\mathrm{BiOCl}$ (Fig. $10 \mathrm{c}$ ), which was ascribed to the characteristic spectrum of DMPO$\mathrm{O}_{2}{ }^{-}$adduct ${ }^{55}$. In addition, the ESR signal increased with irradiation time prolonging from 3 to $10 \mathrm{~min}$. At the same time weak DMPO- $\mathrm{OH}$ adduct ESR signals with the relative intensities of 1:2:2:1 were detected over the 1\% $\mathrm{Bi}_{2} \mathrm{WO}_{6}-\mathrm{BiOCl}$ under the irradiation of sunlight (Fig. 10d). Considering the results of reactive species trapping experiments and ESR characterization, it can be inferred that $\mathrm{O}_{2}{ }^{-}$was the main active species in the photocatalytic process over the $1 \% \mathrm{Bi}_{2} \mathrm{WO}_{6}-\mathrm{BiOCl}$.

The schematic diagrams for $\mathrm{CBM}$ and $\mathrm{VBM}$ electrochemical potentials of $\mathrm{BiOCl}$ and $\mathrm{Bi}_{2} \mathrm{WO}_{6}$ as well as the possible charge separation process of $1 \% \mathrm{Bi}_{2} \mathrm{WO}_{6}-\mathrm{BiOCl}$ are shown in Fig. 11. The CBM potentials ( -1.82 and $-0.95 \mathrm{eV}$ vs. NHE) of $\mathrm{BiOCl}$ and $\mathrm{Bi}_{2} \mathrm{WO}_{6}$ were more negative than the standard redox potential of $\mathrm{O}_{2} / \mathrm{O}_{2}{ }^{-}\left(-0.33 \mathrm{eV}\right.$ vs NHE, pH 7) ${ }^{56}$. The more negative potential than $\mathrm{O}_{2}{ }^{-}$radical allowed the yield of $\mathrm{O}_{2}{ }^{-}$via reduction of adsorbed $\mathrm{O}_{2}$ by photogenerated $\mathrm{e}^{-}$. The $\mathrm{VBM}$ potentials for $\mathrm{Bi}_{2} \mathrm{WO}_{6}$ and $\mathrm{BiOCl}(1.85$ and $1.17 \mathrm{eV}$ $v s$. NHE) were more negative than the standard redox potential edge of $\mathrm{OH} / \mathrm{OH}^{-}(+1.99 \mathrm{eV} v s \mathrm{NHE}, \mathrm{pH} 7)$ and $\mathrm{OH} / \mathrm{H}_{2} \mathrm{O}(+2.27 \mathrm{eV} \mathrm{eV}$ vs NHE, $\mathrm{pH} 7)$, indicating that the photogenerated holes cannot directly oxide $\mathrm{H}_{2} \mathrm{O}$ molecules to $\mathrm{OH}$ radicals ${ }^{57}$.

Based on the above characterizations and DFT calculation results, a possible photocatalytic mechanism for $1 \% \mathrm{Bi}_{2} \mathrm{WO}_{6}-\mathrm{BiOCl}$ is depicated in Fig. 11. The $\mathrm{BiOCl}$ and $\mathrm{Bi}_{2} \mathrm{WO}_{6}$ were exicited simultaneously under simulated sunlight irradiation, the electrons in the VBM were excited into the CBM, and the same amount of holes 


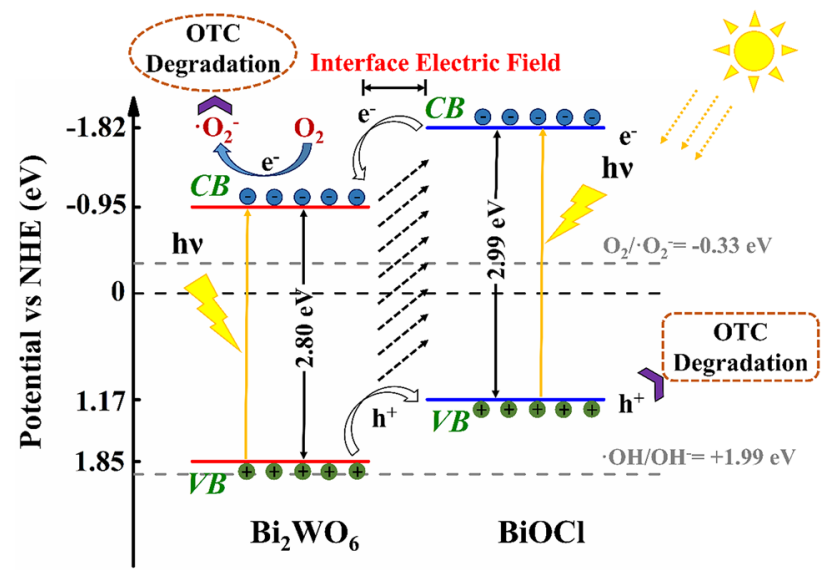

Figure 11. Schematic illustration of band structure diagram and photinduced carriers transfer of $1 \% \mathrm{Bi}_{2} \mathrm{WO}_{6}-$ $\mathrm{BiOCl}$ composites under sunlight irradiation.

$\left(\mathrm{h}^{+}\right)$were remained in the VBM. Since the CBM potential of $\mathrm{BiOCl}(-1.82 \mathrm{eV})$ was more negative than that of $\mathrm{Bi}_{2} \mathrm{WO}_{6}(-0.95 \mathrm{eV})$, the photinduced electrons on the interface of $\mathrm{BiOCl}$ can migrate to the $\mathrm{CBM}$ of $\mathrm{Bi}_{2} \mathrm{WO}_{6}$ by the heterojunction interface in the composite system. Similarly, photogenerated holes on the $\mathrm{Bi}_{2} \mathrm{WO}_{6}$ surface can migrate to $\mathrm{VBM}$ of $\mathrm{BiOCl}$. The electrons in the $\mathrm{Bi}_{2} \mathrm{WO}_{6}$ could be captured by the adsorbed $\mathrm{O}_{2}$ to yield $\mathrm{O}_{2}{ }^{-}$radicals. While the photogenerated holes concentrated on the surface of $\mathrm{BiOCl}$, achieving the efficient separation of the photoinduced electrons and holes on the heterojunction. Moreover the existence of internal electric field could further promote the efficient transfer of photogenerated carriers, thus leading to enhanced photocatalytic activity. The whole process can be described by the following equations:

$$
\begin{gathered}
1 \% \mathrm{Bi}_{2} \mathrm{WO}_{6}-\mathrm{BiOCl} \stackrel{\mathrm{h} v}{\rightarrow} \mathrm{Bi}_{2} \mathrm{WO}_{6}\left(\mathrm{e}^{-}, \mathrm{h}^{+}\right) / \mathrm{BiOCl}\left(\mathrm{e}^{-}, \mathrm{h}^{+}\right) \\
\mathrm{Bi}_{2} \mathrm{WO}_{6}\left(\mathrm{e}^{-}, \mathrm{h}^{+}\right) / \mathrm{BiOCl}\left(\mathrm{e}^{-}, \mathrm{h}^{+}\right) \stackrel{\text { hetero-}}{\rightarrow} \mathrm{Bi}_{2} \mathrm{WO}_{6}\left(\mathrm{e}^{-}\right)+\mathrm{BiOCl}\left(\mathrm{h}^{+}\right) \\
\mathrm{Bi}_{2} \mathrm{WO}_{6}\left(\mathrm{e}^{-}\right)+\mathrm{O}_{2} \rightarrow \mathrm{Bi}_{2} \mathrm{WO}_{6}+\mathrm{O}_{2}^{-} \\
\mathrm{O}_{2}^{-}+\mathrm{OTC} \rightarrow \text { products } \\
\mathrm{BiOCl}\left(\mathrm{h}^{+}\right)+\mathrm{OTC} \rightarrow \text { products }
\end{gathered}
$$

\section{Conclusions}

The $\mathrm{BiOCl}$ nanosheets and $\mathrm{Bi}_{2} \mathrm{WO}_{6}-\mathrm{BiOCl}$ composites were successfully synthesized by the facile hydrothermal and solvothermal process. The photocatalytic activities and mineralization rates of $1 \% \mathrm{Bi}_{2} \mathrm{WO}_{6}-\mathrm{BiOCl}$ for OTC and phenol were superior to individual $\mathrm{BiOCl}$ under simulated sunlight irradiation. The OTC and phenol degradation rates was almost 2.7 and 6.1 times as that of $\mathrm{BiOCl}$, and the mineralization rate of OTC and phenol was 5.3 and 2.8 folds relative to that of $\mathrm{BiOCl}$. The favorable photocatalytic performance was attributed to the synergistic effect of proper bandgap matching, and efficient separation of photogenerated charge carriers as a result of heterojuntion interface effect between $\mathrm{BiOCl}$ and $\mathrm{Bi}_{2} \mathrm{WO}_{6}$, which was verified by the experimental characterizations and DFT calculations. Further experiments demonstrated that the photocatalysis degradation of OTC was due to the oxidation of superoxide radical. Cyclic sunlight irradiation experiments demonstrated the reusability and stability of $1 \% \mathrm{Bi}_{2} \mathrm{WO}_{6}-\mathrm{BiOCl}$. Therefore, it can be concluded that the $\mathrm{Bi}_{2} \mathrm{WO}_{6}-\mathrm{BiOCl}$ heterojunction photocatalyst is a promising candidate for photocatalytic decomposition of organic contaminants.

Received: 22 December 2019; Accepted: 28 September 2020

Published online: 27 October 2020

\section{References}

1. Celik, A., Casey, E. \& Hasar, H. Degradation of oxytetracycline under autotrophic nitrifying conditions in a membrane aerated biofilm reactor and community fingerprinting. J. Hazard. Mater. 356, 26-33 (2018).

2. Liang, F. \& Zhu, Y. Enhancement of mineralization ability for phenol via synergetic effect of photoelectrocatalysis of g- $\mathrm{C}_{3} \mathrm{~N}_{4}$ film. Appl. Catal. B Environ. 180, 324-329 (2016).

3. Jiang, J., Zhao, K., Xiao, X. \& Zhang, L. Synthesis and facet-dependent photoreactivity of BiOCl single-crystalline nanosheets. J. Am. Chem. Soc. 134, 4473-4476 (2012).

4. Niu, P., Zhang, L., Liu, G. \& Cheng, H. M. Graphene-like carbon nitride nanosheets for improved photocatalytic activities. Adv. Funct. Mater. 22, 4763-4770 (2012). 
5. Bai, J. et al. Enhancement of photocatalytic activity of $\mathrm{Bi}_{2} \mathrm{O}_{3}-\mathrm{BiOI}$ composite nanosheets through vacancy engineering. Small 23, 1900020 (2019).

6. Zhao, K. et al. Surface structure-dependent molecular oxygen activation of BiOCl single-crystalline nanosheets. J. Am. Chem. Soc. 135, 15750-15753 (2013).

7. Li, H., Li, J., Ai, Z., Jia, F. \& Zhang, L. Oxygen vacancy-mediated photocatalysis of BiOCl: Reactivity, selectivity, and perspectives. Angew. Chem. Int. Edit. 57, 122-138 (2018).

8. Zhang, X. et al. Synthesis of a highly efficient BiOCl single-crystal nanodisk photocatalyst with exposing 001 facets. ACS Appl. Mater. Inter. 6, 7766-7772 (2014).

9. Ouyang, W., Su, L. \& Fang, X. UV photodetectors based on BiOCl nanosheet arrays: The effects of morphologies and electrode configurations. Small 14, 1801611 (2018).

10. Xiong, J. et al. Tunable BiOCl hierarchical nanostructures for high-efficient photocatalysis under visible light irradiation. Chem. Eng. J. 220, 228-236 (2013).

11. Bai, L. et al. Facet engineered interface design of plasmonic metal and cocatalyst on BiOCl nanoplates for enhanced visible photocatalytic oxygen evolution. Small 13, 1701607 (2017).

12. Bai, S. et al. Toward enhanced photocatalytic oxygen evolution: Synergetic utilization of plasmonic effect and Schottky junction via interfacing facet selection. Adv. Mater. 27, 3444-3452 (2015).

13. Sun, L. et al. Enhanced visible-light photocatalytic activity of $\mathrm{BiOI} / \mathrm{BiOCl}$ heterojunctions: Key role of crystal facet combination. ACS Catal. 5, 3540-3551 (2015).

14. Deng, F. et al. Visible-light-responsive graphene-functionalized Bi-bridge $\mathrm{Z}$-scheme black $\mathrm{BiOCl} / \mathrm{Bi}_{2} \mathrm{O}_{3}$ heterojunction with oxygen vacancy and multiple charge transfer channels for efficient photocatalytic degradation of 2-nitrophenol and industrial wastewater treatment. Appl. Catal. B Environ. 238, 61-69 (2018).

15. Teng, F., Ouyang, W., Li, Y., Zheng, L. \& Fang, X. Novel Structure for high performance UV photodetector based on BiOCl/ZnO hybrid film. Small 13, 1700156 (2017).

16. Wu, Y. et al. Quasi-polymeric construction of stable perovskite-type $\mathrm{LaFeO}_{3} / \mathrm{g}-\mathrm{C}_{3} \mathrm{~N}_{4}$ heterostructured photocatalyst for improved Z-scheme photocatalytic activity via solid pn heterojunction interfacial effect. J. Hazard. Mater. 347, 412-422 (2018).

17. Zhang, N., Ciriminna, R., Pagliaro, M. \& Xu, Y. J. Nanochemistry-derived $\mathrm{Bi}_{2} \mathrm{WO}_{6}$ nanostructures: Towards production of sustainable chemicals and fuels induced by visible light. Chem. Soc. Rev. 43, 5276-5287 (2014).

18. Tian, J. et al. $\mathrm{A} \mathrm{Bi}_{2} \mathrm{WO}_{6}$-based hybrid photocatalyst with broad spectrum photocatalytic properties under UV, visible, and nearinfrared irradiation. Adv. Mater. 25, 5075-5080 (2013).

19. Yang, C. et al. Controlled formation of a flower-like $\mathrm{CdWO} \mathrm{C}_{4}-\mathrm{BiOCl}-\mathrm{Bi}_{2} \mathrm{WO}_{6}$ ternary hybrid photocatalyst with enhanced photocatalytic activity through one-pot hydrothermal reaction. New J. Chem. 42, 9236-9243 (2018).

20. Cao, S., Shen, B., Tong, T., Fu, J. \& Yu, J. 2D/2D Heterojunction of ultrathin $M X e n e / \mathrm{Bi}_{2} \mathrm{WO}_{6}$ nanosheets for improved photocatalytic $\mathrm{CO}_{2}$ reduction. Adv. Funct. Mater. 28, 1800136 (2018).

21. Sun, H., Tian, Z., Zhou, G., Zhang, J. \& Li, P. Exploring the effects of crystal facet in $\mathrm{Bi}_{2} \mathrm{WO}_{6} / \mathrm{BiOCl}$ heterostructures on photocatalytic properties: A first-principles theoretical study. Appl. Surf. Sci. 469, 125-134 (2019).

22. Wu, J., Zhang, W., Tian, Z., Zhao, Y. \& Shen, Z. Facile fabrication of $\mathrm{Bi}_{2} \mathrm{WO}_{6} / \mathrm{BiOCl}$ hierarchical structure as adsorbents for methylene blue dye removal. Mater. Res. Express 6, 055034 (2019).

23. Guan, Z. et al. AgIn $\mathrm{S}_{8}$ nanoparticles anchored on $2 \mathrm{D}$ layered $\mathrm{ZnIn}_{2} \mathrm{~S}_{4}$ to form $0 \mathrm{D} / 2 \mathrm{D}$ heterojunction for enhanced visible-light photocatalytic hydrogen evolution. Appl. Catal. B Environ. 227, 512-518 (2018).

24. Boulesbaa, A. et al. Ultrafast charge transfer and hybrid exciton formation in 2D/0D heterostructures. J. Am. Chem. Soc. 138, 14713-14719 (2016).

25. Wang, K., Zhang, G., Li, J., Li, Y. \& Wu, X. 0D/2D Z-scheme heterojunctions of bismuth tantalate quantum dots/ultrathin g- $\mathrm{C}_{3} \mathrm{~N}_{4}$ nanosheets for highly efficient visible light photocatalytic degradation of antibiotics. ACS Appl. Mater. Inter. 9, 43704-43715 (2017).

26. Wang, K., Li, Y., Zhang, G., Li, J. \& Wu, X. OD Bi nanodots $/ 2 \mathrm{D} \mathrm{Bi}_{3} \mathrm{NbO}_{7}$ nanosheets heterojunctions for efficient visible light photocatalytic degradation of antibiotics: Enhanced molecular oxygen activation and mechanism insight. Appl. Catal. B Environ. 240, 39-49 (2019).

27. Ye, M. Y. et al. $0 \mathrm{D} / 2 \mathrm{D}$ heterojunctions of vanadate quantum dots/graphitic carbon nitride nanosheets for enhanced visible-lightdriven photocatalysis. Angew. Chem. Int. Ed. 56, 8407-8411 (2017).

28. Xu, C. et al. Solvothermal preparation of $\mathrm{Bi}_{2} \mathrm{WO}_{6}$ nanocrystals with improved visible light photocatalytic activity. Mater. Lett. 63, 2194-2197 (2009).

29. Wang, Y., Yang, W., Chen, X., Wang, J. \& Zhu, Y. Photocatalytic activity enhancement of core-shell structure g- $\mathrm{C}_{3} \mathrm{~N}_{4} @ \mathrm{TiO}_{2}$ via controlled ultrathin g- $\mathrm{C}_{3} \mathrm{~N}_{4}$ layer. Appl. Catal. B Environ. 220, 337-347 (2018).

30. Liu, Y. et al. Significant role of UV and carbonate radical on the degradation of oxytetracycline in UV-AOPs: Kinetics and mechanism. Water Res. 95, 195-204 (2016).

31. Kresse, G. \& Furthmuller, J. Efficient iterative schemes for ab initio total-energy calculations using a plane-wave basis set. Phys. Rev. B. 54, 11169-11186 (1996).

32. Kresse, G. \& Furthmuller, J. Efficiency of ab-initio total energy calculations for metals and semiconductors using a plane-wave basis set. Comp. Mater. Sci. 6, 15-50 (1996).

33. Blochl, P. E. Projector augmented-wave method. Phys. Rev. B. 50, 17953-17979 (1994).

34. Perdew, J. P. \& Wang, Y. Accurate and simple analytic representation of the electron-gas correlation energy. Phys. Rev. B. 45, 13244-13249 (1992).

35. Yang, W., Wen, Y., Chen, R., Zeng, D. \& Shan, B. Study of structural, electronic and optical properties of tungsten doped bismuth oxychloride by DFT calculations. Phys. Chem. Chem. Phys. 16, 21349-21355 (2014).

36. Ahsaine, H. A. et al. Electronic band structure and visible-light photocatalytic activity of $\mathrm{Bi}_{2} \mathrm{WO}_{6}$ : Elucidating the effect of lutetium doping. RSC Adv. 6, 101105-101114 (2016).

37. Yu, C. et al. Novel fluorinated $\mathrm{Bi}_{2} \mathrm{MoO}_{6}$ nanocrystals for efficient photocatalytic removal of water organic pollutants under different light source illumination. Appl. Catal. B Environ. 209, 1-11 (2017).

38. Li, Q. et al. Z-scheme BiOCl-Au-CdS heterostructure with enhanced sunlight-driven photocatalytic activity in degrading water dyes and antibiotics. ACS Sustain. Chem. Eng. 5, 6958-6968 (2017).

39. Zhou, Y. et al. Monolayered $\mathrm{Bi}_{2} \mathrm{WO}_{6}$ nanosheets mimicking heterojunction interface with open surfaces for photocatalysis. Nat. Commun. 6, 8340 (2015).

40. Zhang, C. et al. In situ fabrication of $\mathrm{Bi}_{2} \mathrm{WO}_{6} / \mathrm{MoS}_{2} / \mathrm{RGO}$ heterojunction with nanosized interfacial contact via confined space effect toward enhanced photocatalytic properties. ACS Sustain. Chem. Eng. 4, 5936-5942 (2016).

41. Tian, Y.et al. Fabrication of hollow mesoporous $\mathrm{SiO}_{2}-\mathrm{BiOCl@PANI@Pd} \mathrm{photocatalysts} \mathrm{to} \mathrm{improve} \mathrm{the} \mathrm{photocatalytic} \mathrm{performance}$ under visible light. Appl. Catal. B Environ. 213, 136-146 (2017).

42. Yue, L. et al. Novel MWNTs- $\mathrm{Bi}_{2} \mathrm{WO}_{6}$ composites with enhanced simulated solar photoactivity toward adsorbed and free tetracycline in water. Appl. Catal. B Environ. 176, 11-19 (2015).

43. Shi, Y. et al. In-situ topotactic synthesis and photocatalytic activity of plate-like $\mathrm{BiOCl} / 2 \mathrm{D}$ networks $\mathrm{Bi}_{2} \mathrm{~S}_{3}$ heterostructures. Appl. Catal. B Environ. 220, 570-580 (2018).

44. Zhang, X. et al. Facile composition-controlled preparation and photocatalytic application of $\mathrm{BiOCl} / \mathrm{Bi}_{2} \mathrm{O}_{2} \mathrm{CO}_{3}$ nanosheets. Appl. Catal. B Environ. 150, 486-495 (2014). 
45. Ju, P. et al. A novel calcined $\mathrm{Bi}_{2} \mathrm{WO}_{6} / \mathrm{BiVO}_{4}$ heterojunction photocatalyst with highly enhanced photocatalytic activity. Chem. Eng. J. 236, 430-437 (2014).

46. Ma, D., Zhong, J., Peng, R., Li, J. \& Duan, R. Effective photoinduced charge separation and photocatalytic activity of hierarchical microsphere-like $\mathrm{C}_{60} /$ BiOCl. Appl. Surf. Sci. 465, 249-258 (2019).

47. Hao, L., Huang, H., Guo, Y., Du, X. \& Zhang, Y. Bismuth oxychloride homogeneous phasejunction $\mathrm{BiOCl} / \mathrm{Bi}_{12} \mathrm{O}_{17} \mathrm{Cl}_{2}$ with unselectively efficient photocatalytic activity and mechanism insight. Appl. Surf. Sci. 420, 303-312 (2017).

48. Zhang, K. et al. Self-assembled perylene diimide based supramolecular heterojunction with $\mathrm{Bi}_{2} \mathrm{WO}_{6}$ for efficient visible-light-driven photocatalysis. Appl. Catal. B Environ. 232, 175-181 (2018).

49. Jia, X. et al. One-pot synthesis of novel flower-like $\mathrm{BiOBr}_{0.9} \mathrm{I}_{0.1}, \mathrm{BiOI}$ heterojunction with largely enhanced electron-hole separation efficiency and photocatalytic performances. J. Mol. Catal. A-Chem. 409, 94-101 (2015).

50. Sánchez-Rodríguez, D., Medrano, M. G. M., Remita, H. \& Escobar-Barrios, V. Photocatalytic properties of $\mathrm{BiOCl}^{-\mathrm{TiO}_{2}}$ composites for phenol photodegradation. J. Environ. Chem. Eng. 6, 1601-1612 (2018).

51. Zuo, Y., Wang, C., Sun, Y. \& Cheng, J. Preparation and photocatalytic properties of $\mathrm{BiOCl} / \mathrm{Bi}_{2} \mathrm{MoO}_{6}$ composite photocatalyst. Mater. Lett. 139, 149-152 (2015).

52. Dong, S. et al. Self-assembled hollow sphere shaped $\mathrm{Bi}_{2} \mathrm{WO}_{6} / \mathrm{RGO}$ composites for efficient sunlight-driven photocatalytic degradation of organic pollutants. Chem. Eng. J. 316, 778-789 (2017).

53. Zhang, K. et al. $\mathrm{Co}-\mathrm{Pd} / \mathrm{BiVO}_{4}$ : High-performance photocatalysts for the degradation of phenol under visible light irradiation. Appl. Catal. B Environ. 224, 350-359 (2018).

54. Wan, Z., Zhang, G., Wu, X. \& Yin, S. Novel visible-light-driven Z-scheme $\mathrm{Bi}_{12} \mathrm{GeO}_{20} / \mathrm{g}-\mathrm{C}_{3} \mathrm{~N}_{4}$ photocatalyst: Oxygen-induced pathway of organic pollutants degradation and proton assisted electron transfer mechanism of $\mathrm{Cr}(\mathrm{VI})$ reduction. Appl. Catal. $B$ Environ. 207, 17-26 (2017).

55. Chen, F. et al. Hierarchical assembly of graphene-bridged $\mathrm{Ag}_{3} \mathrm{PO}_{4} / \mathrm{Ag} / \mathrm{BiVO}_{4}(040) \mathrm{Z}$-scheme photocatalyst: An efficient, sustainable and heterogeneous catalyst with enhanced visible-light photoactivity towards tetracycline degradation under visible light irradiation. Appl. Catal. B Environ. 200, 330-342 (2017).

56. Wang, C. Y. et al. Photocatalytic degradation of bisphenol A by oxygen-rich and highly visible-light responsive $\mathrm{Bi}_{12} \mathrm{O}_{17} \mathrm{Cl}_{2}$ nanobelts. Appl. Catal. B Environ. 200, 659-665 (2017).

57. Deng, Y. et al. Insight into highly efficient simultaneous photocatalytic removal of $\mathrm{Cr}(\mathrm{VI})$ and 2,4-diclorophenol under visible light irradiation by phosphorus doped porous ultrathin $\mathrm{g}_{-} \mathrm{C}_{3} \mathrm{~N}_{4}$ nanosheets from aqueous media: Performance and reaction mechanism. Appl. Catal. B Environ. 203, 343-354 (2017).

\section{Acknowledgements}

This work was financially supported by the Natural Science Foundation of China (21876084).

\section{Author contributions}

X.C. and M.G. conceived the project. X.C., F.M., S.L., and M.G. designed the experiments; M.G., S.Y. and P.Z. carried out the experiment; Z.Z. and J.W. performed the DFT calculation; M.G. carried out data analysis and interpretation; M.G., S.L. and X.C. co-wrote the paper with all authors contributing to the discussion and preparation of the manuscript.

\section{Competing interests}

The authors declare no competing interests.

\section{Additional information}

Correspondence and requests for materials should be addressed to X.C.

Reprints and permissions information is available at www.nature.com/reprints.

Publisher's note Springer Nature remains neutral with regard to jurisdictional claims in published maps and institutional affiliations.

(c) (i) Open Access This article is licensed under a Creative Commons Attribution 4.0 International

License, which permits use, sharing, adaptation, distribution and reproduction in any medium or format, as long as you give appropriate credit to the original author(s) and the source, provide a link to the Creative Commons licence, and indicate if changes were made. The images or other third party material in this article are included in the article's Creative Commons licence, unless indicated otherwise in a credit line to the material. If material is not included in the article's Creative Commons licence and your intended use is not permitted by statutory regulation or exceeds the permitted use, you will need to obtain permission directly from the copyright holder. To view a copy of this licence, visit http://creativecommons.org/licenses/by/4.0/.

(C) The Author(s) 2020 